OPEN ACCESS

Edited by:

Ertugrul Kilic,

Istanbul Medipol University, Turkey

Reviewed by:

Ahmet Burak Caglayan,

Istanbul Medipol University, Turkey Hulya Karatas,

Hacettepe University, Turkey

*Correspondence:

Lijuan Gu

gulijuan@whu.edu.cn Xiaoxing Xiong

xiaoxingxiong@whu.edu.cn

tThese authors have contributed equally to this work

Specialty section

This article was submitted to Cellular Neuropathology,

a section of the journal

Frontiers in Cellular Neuroscience

Received: 12 January 2021

Accepted: 16 February 2021

Published: 21 April 2021

Citation:

Zhu H, Zhang Y, Zhong Y, Ye Y, Hu X, Gu L and Xiong $X$ (2021) Inflammation-Mediated Angiogenesis in Ischemic Stroke.

Front. Cell. Neurosci. 15:652647. doi: 10.3389/fncel.2021.652647

\section{Inflammation-Mediated Angiogenesis in Ischemic Stroke}

\author{
Hua Zhu ${ }^{1,2 t}$, Yonggang Zhang ${ }^{1,2 t}$, Yi Zhong ${ }^{1}$, Yingze Ye ${ }^{1}$, Xinyao Hu ${ }^{3}$, Lijuan $\mathrm{Gu}^{2,4 *}$ and \\ Xiaoxing Xiong ${ }^{1,2 *}$
}

${ }^{1}$ Department of Neurosurgery, Renmin Hospital of Wuhan University, Wuhan, China, ${ }^{2}$ Central Laboratory, Renmin Hospital of Wuhan University, Wuhan, China, ${ }^{3}$ Department of Oncology, Renmin Hospital of Wuhan University, Wuhan, China,

${ }^{4}$ Department of Anesthesiology, Renmin Hospital of Wuhan University, Wuhan, China

Stroke is the leading cause of disability and mortality in the world, but the pathogenesis of ischemic stroke (IS) is not completely clear and treatments are limited. Mounting evidence indicate that neovascularization is a critical defensive reaction to hypoxia that modulates the process of long-term neurologic recovery after IS. Angiogenesis is a complex process in which the original endothelial cells in blood vessels are differentiated, proliferated, migrated, and finally remolded into new blood vessels. Many immune cells and cytokines, as well as growth factors, are directly or indirectly involved in the regulation of angiogenesis. Inflammatory cells can affect endothelial cell proliferation, migration, and activation by secreting a variety of cytokines via various inflammation-relative signaling pathways and thus participate in the process of angiogenesis. However, the mechanism of inflammation-mediated angiogenesis has not been fully elucidated. Hence, this review aimed to discuss the mechanism of inflammation-mediated angiogenesis in IS and to provide new ideas for clinical treatment of IS.

Keywords: angiogenesis, stroke, immune cells, inflammation, inflammatory cytokine

\section{INTRODUCTION}

Ischemic stroke (IS) is one of the diseases with the highest incidence and disability rate in the world. Currently, the effective treatment measure for IS is thrombolytic therapy with tissue plasminogen activator to recirculate cerebral blood flow. However, due to the limitation of the treatment time window, only a small number of patients are suited to this treatment (Zhou et al., 2019). Thus, clarifying the pathogenesis and exploring new therapies are urgently needed to improve outcomes. Normal collateral circulation can effectively improve the blood flow supply of brain tissue. The extension of neovascularization from normal brain tissue to the ischemic penumbra and central necrotic area can improve the blood perfusion of the surrounding ischemic area, reduce the volume of cerebral infarction, remold the nerve structure, and restore the central nervous system (CNS) function. Therefore, more and more studies have been conducted to promote the formation of neovascularization in the ischemic and surrounding areas after IS. Immune cells, such as mononuclear macrophages, $\mathrm{T}$ cells, and microglia, are involved in angiogenesis after stroke through different mechanisms. Here, we focus on the role of immune cells and related cytokines in neurovascular remodeling after IS and discuss the potential therapies for stroke that target neurovascular remodeling. 


\section{OVERVIEW OF ANGIOGENESIS}

Angiogenesis, known as the formation of neovascularization that is induced by the sprouting of endothelial cells (ECs) from preexisting vessels, occurs under a variety of physiological (e.g., reproduction) and pathological (e.g., IS) conditions (Potente et al., 2011). During the sprouting process, ECs degrade the basement membrane, migrate into adjacent tissues, proliferate, and aggregate into tubes to form new blood vessels and establish blood flow. Basement membrane starts to form under the joint action of pericytes, ECs, and the microenvironment and further promotes the maturation and stability of new tubes, then finally completes the vascular remodeling (Marti et al., 2000). The proliferation and migration of ECs, increased vascular permeability, and the degradation of the surrounding stroma, as well as the stabilization and cessation of angiogenesis, are essential steps of angiogenesis (Hayashi et al., 2003). Under physiological state, angiogenesis is in the dynamic balance of the angiogenesis-promoting factor and the inhibiting factor. Once the balance is broken, insufficient angiogenesis will lead to slow wound healing, such as stroke. Angiogenesis can salvage cerebral blood flow and supply nutrients/oxygen to the ischemic brain tissue, finally rescuing grievous neurons and impaired tissues (Krupinski et al., 1994). An elevated vascular density in the brain ischemic penumbra region was observed 3 days after IS in animal and human brain specimens (Hayashi et al., 2003). Excessive angiogenesis is commonly seen in the occurrence, development, and metastasis of tumors.

\section{THE ROLE OF ANGIOGENESIS IN IS}

Stroke is usually the result of focal cerebral ischemia caused by cerebral stenosis or occlusion. The blood flow of the brain tissue in the cerebrovascular region drops sharply, leading to a sharp decrease in the supply of oxygen and nutrients and eventually leading to tissue cell damage and even death. The potential mechanism of compensatory increased oxygen supply to ischemic brain tissue is the induction of new vessels. Neovascularization in the ischemic infarction area regulates the cerebral blood flow, neuron repair and regeneration, and the degree of functional recovery of patients as well as the functional reconstruction or rebuilding of synaptic connections between nerve cells (Pan et al., 2010). The collateral circulation in the initial phase of IS relies on the opening of a preexisting vascular network, while in the later period, it mainly depends on the formation of new blood vessels. New blood vessels begin to be observed at 3 days after IS and increase continuously for 21 days or more (del Zoppo and Mabuchi, 2003). Angiogenesis after stroke has therapeutic potential. Postmortem examination of the cerebral tissue of stroke patients with different survival times showed that the density of microvessels on the infarcted side was notably higher than that of the normal hemisphere on the opposite side. The number of new blood vessels around the infarct is positively correlated with the survival rate, survival time, and neurological function recovery of stroke patients (Krupinski et al., 1994). Other studies have found that patients with dementia show severe decreased cerebral blood flow in non-infarcted areas, indicating that angiogenesis can improve patients' daily activities by increasing cerebral blood flow (Schmidt et al., 2000). In a mouse model of middle cerebral artery occlusion (MCAO), proliferating ECs were found in the ischemic penumbra and were associated with increased vascular density (Kim et al., 2020). The ischemic penumbra, a structurally intact but functionally impaired region around the ischemic core area after cerebral infarction, is the main target of therapeutic intervention. Further exploration of the mechanism of angiogenesis after IS is conducive to research on more treatment options.

\section{INFLAMMATORY-MEDIATED ANGIOGENESIS AFTER IS}

Previous studies have identified that various immune cell subgroups regulate angiogenesis, such as natural killer (NK) cells, T helper 17 (Th17) cells, regulatory $\mathrm{T}$ lymphocytes (Tregs), and a functional subset of macrophages (M2 macrophages) (la Sala et al., 2012). Numerous angiogenic growth factors, commonly associated with inflammatory response, including vascular endothelial growth factor (VEGF), tumor necrosis factor$\alpha($ TNF- $\alpha)$, monocyte chemotactic protein-1 (MCP-1/CCL2), transforming growth factor- $\beta$ (TGF- $\beta$ ), fibroblast growth factor (FGF), granulocyte-macrophage colony-stimulating factor (GMCSF)/granulocyte colony-stimulating factor (G-CSF), hepatocyte growth factor (HGF), platelet-derived growth factor (PDGF), and interleukins (ILs), play crucial roles in inflammatory-mediated angiogenesis after IS (Schierling et al., 2009). The molecular mechanisms of inflammation-mediated angiogenesis involved in IS are discussed below.

\section{THE ROLE OF IMMUNE CELL SUBSETS AND INFLAMMATORY CELLS IN ANGIOGENESIS AFTER IS}

\section{NK Cells}

NK cells, an important subgroup of immune cells, infiltrate into local ischemic brain tissue and act as a bridge between the immune system and the CNS in IS patients. NK cells are closely associated with immunosuppression, inflammation, and infection after IS (Chen et al., 2019). Studies have confirmed that in pathological and physiological conditions, NK cells produce cytokines that promote angiogenesis and independently regulate angiogenesis (Ribatti et al., 2019). IS leads to other complications, such as cerebral small vessel disease. In the cerebral microvasculature of spontaneously hypertensive (a model for early-onset cerebral small vessel disease) rats after IS, NK cells infiltrated markedly in the cerebral microvessels, leading to inflammatory reactions and hypertension-associated cognitive dysfunction (Kaiser et al., 2014). The activated NK cells are involved in endothelial and vascular function deficits by promoting the expression of interferon gamma (IFN$\gamma$ ) (Kossmann et al., 2013). Angiogenesis is an important compensation method for arterial obstruction. In addition, NK 
cells play crucial roles in cerebrovascular formation in hindlimb ischemia mice (van Weel et al., 2007).

\section{CD4 $^{+}$T Cells}

$\mathrm{CD}^{+}{ }^{+} \mathrm{T}$ cells (consisting of Th1, Th2, Th17, and Tregs), which are responsible for inflammatory response, boost arteriogenesis in a murine model of hindlimb ischemia (Nossent et al., 2017). Moreover, $\mathrm{CD}^{+}{ }^{+} \mathrm{T}$ cells play essential roles in activating and polarizing macrophages, which have been demonstrated to have the ability to promote angiogenesis (Zhang et al., 2020). Th17 promotes angiogenesis and increases cerebral blood flow in the ischemic penumbra, partly owing to its potent effect in promoting the migration and sprouting of ECs (Kwee et al., 2018). The study has shown that hyperforin could promote subependymal ventricular zone angiogenesis, neurogenesis, and functional recovery through suppressing Th1 cell differentiation while facilitating Th2/Treg cell differentiation in the ischemic area, which is mediated by astrocyte IL-6 (Yao et al., 2019). Hence, it indicates that the infiltration of Th2 cells into the ischemic hemisphere increased Th2-derived cytokine IL-4, increased Tregderived IL-10 and TGF- $\beta$, as well as decreased Th1 and Th1derived cytokine IFN- $\gamma$, which are all key events that promote angiogenesis during stroke recovery.

\section{Microglia/Macrophage Cells}

Resident microglia and infiltrated macrophages activate the immune defense in the CNS to regulate the inflammatory condition dynamically in the injured brain (Zhu et al., 2019). Microglia/macrophages can polarize into the M1 and M2 phenotypes to participate in IS damage or repair (Liu et al., 2018). M1 is known to be classically activated and to exert proinflammatory effects, whereas M2 is alternatively activated and plays an anti-inflammatory role in IS. M2 macrophages, a more heterogeneous phenotype, can be further divided into M2a and M2c according to their function. The M2a subset activated by IL4 is regarded as the wound healing macrophages that also belong to the alternatively activated macrophages; the M2c subgroup activated by numerous stimulants, including glucocorticoids, immune complexes, and IL-10, as well as prostaglandins, is known as the regulatory macrophages.

Microglial/macrophage cells are also crucial to angiogenesis after IS. Evidence shows that increased microvessel density after IS was detected only in the regions also containing macrophages, suggesting that angiogenesis is related to the increased number of macrophages (Manoonkitiwongsa et al., 2001). Moreover, the brain may synthesize microvessels and open capillaries needed for macrophage infiltration for the destruction and removal of necrotic brain tissue via the angiogenic signaling cascade. Microglial activation and the related neuroinflammation in the ischemic penumbra region were alleviated by polarizing the microglia toward the M2 phenotype (Shang et al., 2020). Previous studies have indicated that M2 microglia/macrophages have a higher potential to promote angiogenesis than other subgroups. Moreover, FGF signaling for M2a- and placenta growth factor (PlGF) signaling for $\mathrm{M} 2 \mathrm{c}$-induced angiogenesis may be the possible working mechanisms (Jetten et al., 2014). Hence, further researches are needed to illustrate the exact mechanism of angiogenesis induced by M2.

\section{Brain Pericytes}

Brain pericytes are perivascular cells that play a critical role in the regulation of capillary function and the development of cerebral microcirculation, and their location puts them in a crucial position to regulate the neuroinflammation at the neurovascular unit (NVU), which consists of neuronal cells, pericytes, ECs, astrocytes, microglia, and the extracellular matrix (Bell et al., 2010; Muoio et al., 2014). Brain pericytes are involved in a variety of brain functions, such as the generation and stabilization of the blood-brain barrier (BBB), brain inflammation, and tissue regeneration, as well as the propagation of CNS and peripheral inflammation (Umehara et al., 2018). Moreover, pericytes recently have been verified to exert many functions of immunomodulatory cells, including producing and responding to inflammatory cytokines, presenting antigen, and exhibiting phagocytosis. Hence, brain pericytes are increasingly considered to be mediators of neuroinflammation (Rustenhoven et al., 2017), thereby participating in inflammatory reaction during IS.

Previous studies have shown that the continuous constriction and necrocytosis of pericytes in the hyperacute phase leads to the no-reflow phenomenon, and the inflammatory responses and the separation of pericytes in the acute phase may exacerbate the BBB injury (Uemura et al., 2020). However, pericytes also exert a neuroprotective role via releasing neurotrophins, EC protection, and BBB stabilization (Franco et al., 2011; Winkler et al., 2011; Ishitsuka et al., 2012). Pericytes play a powerful role in neural restoration after IS via promoting angiogenesis and neurogenesis. The bidirectional ECs-pericytes signaling is essential during angiogenesis (Stapor et al., 2014). Firstly, after being stimulated by pro-angiogenic factors, pericytes produce numerous matrix metalloproteinases (MMPs) (MMP-2, MMP3, and MMP-9) to degrade the components of the basement membrane, resulting in the separation of pericytes and the succeeding release of ECs (Virgintino et al., 2007; CandelarioJalil et al., 2009; Potente et al., 2011). Furthermore, increased vascular permeability promotes plasma protein extravasation and provides a temporary scaffold for vascular germination (Carmeliet and Collen, 2000). In addition, pericytes generate VEGF-A, which activates ECs to protrude filopodia, leading to the formation of tip cells (Jakobsson et al., 2010; Franco et al., 2011). Then, stalk cells multiply to support the extension of sprouts and construct a vascular vessel (Eilken and Adams, 2010). Meanwhile, pericytes adhere to ECs, regulate the sediment of the extracellular matrix and the modeling of the inter-endothelial tight junctions, and stabilize neovascularization. Lastly, tip cells anastomose with adjacent sprouts to form microvascular rings (Jain, 2003). Then, pericytes are transformed to suppress EC multiplication and reestablish the quiescence state of ECs to stop angiogenesis (Yang et al., 2017). The primary pericyte-associated pathways propelling neovascularization after IS include the PDGF-BB/PDGFR $\beta$ pathway (Gaengel et al., 2009), VEGFA/VEGFR2 pathway (Greenberg and Jin, 2005), TGF- $\beta$ /TGFR $\beta 2$ pathway (Walshe et al., 2009; Li et al., 2011), Notch pathway (Kume, 2012), and the Ang/Tie2 pathway (Armulik et al., 2011). 
Here, we have roughly concluded the mechanism of pericytes involved in angiogenesis after IS; further studies are needed to elucidate the mechanism of angiogenesis after IS and to explore feasible pro-angiogenic therapies.

\section{THE ROLE OF INFLAMMATORY CYTOKINES IN ANGIOGENESIS AFTER IS VEGF}

VEGF, diffusely distributed in brain tissue, has essential effects in brain inflammation through promoting inflammatory cell recruitment and adjusting angiopoietin II (Ang II) secretion (Yin et al., 2020). VEGFs and their receptors (VEGFRs) are also pivotal regulators of blood vessel formation. VEGF is mainly divided into matrix-bound and soluble subtypes. Matrixbound subtypes stimulate more vessel branching, while soluble VEGF facilitates vascular dilation (Carmeliet, 2003). The VEGF family consists of seven subsets of ligands: VEGF-A, VEGFB, VEGF-C, VEGF-D, VEGF-E, VEGF-F, and PlGF. PlGF, VEGF-A, and VEGF-B are required for angiogenesis (Takahashi and Shibuya, 2005). VEGF-A (also known as VEGF) is the major member of the VEGF family and promotes angiogenesis via binding to VEGF receptor-2 (VEGFR-2) (Zhong et al., 2020). VEGF-B, functionally and structurally related to VEGF$\mathrm{A}$ and PlGF, regulates the bioavailability of VEGF-A (Olofsson et al., 1996). The binding of VEGFs to their receptors on the cytomembrane of ECs activates the mitogen-activated protein kinase (MAPK)/extracellular signal-regulated kinase (ERK) $1 / 2$ and phosphatidylinositol-3 kinase (PI3K)/protein kinase $\mathrm{B}(\mathrm{AKT})$ pathways, leading to EC survival, proliferation, differentiation, migration, and tube formation (Assareh et al., 2019). Deficiency of VEGF and/or VEGFR-2 leads to vascular formation defects. In addition, the biological effects of VEGFR-2 may vary greatly due to its subcellular localization. For example, VEGFR-2 must signal from the endocellular compartments when VEGF induces arterial morphogenesis (Lanahan et al., 2010). In addition, autocrine VEGF, secreted by ECs, maintains vascular stabilization (Lee et al., 2007), whereas paracrine VEGF, produced by myeloid, tumor, or stromal cells, renders tumor vessels abnormal and increase vessel branching (Stockmann et al., 2008). Endostatin inhibited VEGF-induced endothelial tube formation by stabilizing the newly formed endothelial tubes (Ergün et al., 2001). Hence, endostatin may be a new anti-angiogenic agent in tumor therapy.

As a potent angiogenic factor, VEGF also has neuroprotective activity. A previous study has illustrated that VEGF promotes neurovascular remodeling in the ischemic hemisphere, contralesional corticobulbar plasticity, and neurological recovery. This brain remodeling by VEGF may be achieved by the deactivation of MMP9, activation of c-Jun, and the suppression of caspase-3-dependent apoptotic cell death as well as the downregulation of growth inhibitory proteoglycans and guidance molecules (Reitmeir et al., 2012). In addition, VEGF has been reported to attenuate the CD45 ${ }^{+}$leukocyte infiltrates at 14 days after ischemia and to diminish the activation of the microglia. Intracerebroventricularly delivered VEGF promotes contralesional corticorubral plasticity through its anti-inflammatory action via the downregulation of a broad set of inflammatory cytokines and chemokines in both brain hemispheres (Herz et al., 2012). Although the overexpression of VEGF exerts neuroprotection after IS, VEGF facilitates a hemodynamic steal phenomena with reduced blood flow in ischemic areas and increased flow values only outside the MCA territory. The overexpression of VEGF can significantly alleviate neurological deficits and infarct volume and reduce the disseminated neuronal injury and caspase-3 activity, confirming that VEGF has neuroprotective properties. However, a mild blood-brain barrier leakage has been reported to be induced by VEGF (Wang et al., 2005). Hence, the overexpression of VEGF may worsen rather than improve cerebral hemodynamics after IS. The survival-enhancing effect of VEGF is purchased at the expense of increased BBB permeability, which may be regulated by the PI3K/AKT pathway (Kilic et al., 2006). Taken together, the neuroprotective functions of VEGF cannot be easily exploited without accepting the adverse consequences of increased vascular permeability.

\section{MCP-1}

MCP-1, also known as CCL2, a key chemokine that regulates the activation and recruitment of monocytes and microglias as well as $\mathrm{T}$ cells, has been implicated in inflammatory and angioproliferative CNS disease (Zhang and Luo, 2019). Both MCP-1 and its receptor $\mathrm{C}-\mathrm{C}$ chemokine receptor type 2 (CCR2) expressed in the brain are crucial regulators of CNS inflammation and activation of the microglia, involved in various neuroinflammatory diseases (Hinojosa et al., 2011). During inflammatory response, MCP-1 attracts peripheral monocytes to the brain and regulates Th cell development by stimulating Th2 polarization (Saoud et al., 2019). Coincidentally, we have discussed above that the infiltration of Th2 cells to the ischemic hemisphere and the increased Th2-derived cytokine IL-4 can promote angiogenesis during stroke recovery. MCP1 is also acknowledged as an angiogenic chemokine. However, the mechanism of angiogenesis mediated by MCP-1 has not been fully elucidated. Previous studies indicate that MCP-1mediated angiogenesis mainly consists of two successive steps: the expression of VEGF-A gene induced by MCP-1 and the subsequent neovascularization induced by VEGF-A. MCP-1 upregulates the expression of the hypoxia-inducible factor 1 alpha (HIF-1 $\alpha)$ gene in human aortic ECs, which induces VEGFA expression in the human aortic wall and ECs via activating MAPK (Hong et al., 2005). A previous study has illustrated that VEGF also induces the expression of MCP-1, mainly through activating NF-kB and the activator protein 1 (AP-1) in retinal ECs (Marumo et al., 1999). MCP-1-mediated angiogenesis is also induced by MCP-1-induced protein (MCPIP), at least partly via the transcriptional activation of cadherin (cdh) 12 and cdh19. Additionally, MCP-1 is involved in neurological recovery after IS and delivers varieties of cells into the brain through MCP1/CCR2 interplay. Moreover, after intravenous transplantation of human umbilical cord-derived mesenchymal stem cells (hUC-MSCs) with overexpression of MCP-1 in MCAO rats, angiogenesis was promoted in the ischemic penumbra region 
(Lee et al., 2020). This indicates that MCP-1-overexpressing hUC-MSCs distinctly repaired functional deficits in rats with MCAO by accelerating persistent increases in MCP-1 levels in brain tissue, promoting neurogenesis and angiogenesis and inhibiting neuroinflammation. These results demonstrate that MCP-1-overexpressing MSCs might be an alternative therapeutic method for cell therapy of IS.

\section{TNF- $\alpha$}

TNF- $\alpha$, a cytokine with diverse pro-inflammatory actions, plays crucial roles in both pathological and physiological conditions (Saha and Smith, 2018). TNF- $\alpha$ is induced in the ischemic cerebral tissue within $1 \mathrm{~h}$, peaks at $6-10 \mathrm{~h}$, and subsides $1-$ 2 days post-IS (Liu et al., 1994). Increased TNF- $\alpha$ exerts both neuroprotective and neurotoxic effects after IS (Wilde et al., 2000). TNF- $\alpha$ acts via interacting with two kinds of receptors, TNF receptor 1 (TNFR1) and TNFR2, which can mediate hindlimb ischemia-induced angiogenesis (Luo et al., 2006). Researches in neuroprotection have shown that TNFR1 targeting the erythropoietin receptor (EPOR) and VEGF can alleviate cortical neuronal injury after IS (Taoufik et al., 2008). Moreover, the interplay between TNF- $\alpha$ and TNFR1 primes brain ECs for erythropoietin (EPO)-enhanced angiogenesis by the upregulation of EPOR that amplifies the effect of EPO on the activation of VEGF/VEGFR2 and the angiopoietin 1 (Ang1)/angiopoietin receptor (Tie2) signaling pathway (Wang et al., 2011). In addition, TNF/TNFR1 can act directly on ECs to regulate angiogenesis via activating VEGF signaling (Sugano et al., 2004). TNF also activates various pathways, such as NF-кB and AKT. The NF- $\kappa \mathrm{B}$ activated by TNF may trigger the activation of AKT signaling, whereas both NF- $\mathrm{B}$ and PI3K/AKT pathways are essential for the TNF/TNFR1-upregulated expression of EPOR (Wang et al., 2011). These evidences certify the network between TNF/TNFR1 and EPOR to coordinate the occurrence of neovascularization in brain ECs. Additionally, other studies illuminated that IS-induced angiogenesis relies on the TNFR1mediated upregulation of $\alpha 5 \beta 1$ and $\alpha \mathrm{V} \beta 3$ integrins (Huang et al., 2016).

\section{TGF- $\beta$}

The TGF- $\beta$ s consist of three mammalian subtypes (TGF- $\beta 1$, TGF- $\beta 2$, and TGF- $\beta 3$ ). The component of TGF- $\beta$ signaling transduction, including the serine kinase-type receptor on the cytomembrane, exists in the CNS. TGF- $\beta$ s are pluripotent cytokines whose potential neuroprotective actions are gradually acknowledged. Actually, the expression of TGF- $\beta$ can be activated following various brain injuries. The neuroprotective action of TGF- $\beta$ is mostly induced by IS (Dobolyi et al., 2012). Injury in animal models of local and global cerebral ischemia was observed to be suppressed by TGF- $\beta$ s. A previous study has shown that TGF- $\beta$ s inhibit microglias, thereby exerting an antiinflammatory effect (Lund et al., 2018). Since the microglia is the main source of TGF- $\beta 1$ in the CNS, they may have an autoinhibitory effect on the microglia (Lenzlinger et al., 2001). The potential neuroprotective mechanisms of TGF- $\beta$ s include anti-inflammatory, anti-excitotoxic, and anti-apoptotic abilities and the facilitation of angiogenesis, neurogenesis, and scar formation.

The secretion of TGF- $\beta 1$ was proven following IS damage. The expression of TGF- $\beta 1$ in the ischemic penumbra region was significantly elevated after MCAO in baboons and rats (Ali et al., 2001; Vincze et al., 2010). Moreover, increased levels of TGF- $\beta 1$ were also found in human brain following IS (Krupinski et al., 1996). Activated microglia/macrophages have been demonstrated to be the primary sources of TGF- $\beta 1$ messenger RNA (mRNA) after focal ischemic attack (Lehrmann et al., 1998; Doyle et al., 2010). In addition, astrocytes and neuronal cells may also contribute to the upregulated TGF- $\beta 1$ expression after IS (Zhu et al., 2001; Malik et al., 2020).

TGF- $\beta$ is known to facilitate angiogenesis. After subcutaneous injection of TGF- $\beta$ in neonatal mice, collagen production by fibroblasts and increased angiogenesis were observed at the injection site (Roberts et al., 1986). A previous study has demonstrated that TGF- $\beta 1$ can enhance the actions of other growth factors. In fact, TGF- $\beta 1$ amplified the therapeutic action of VEGF-induced angiogenesis in patients with peritoneal dialysis (Kariya et al., 2018). Using a two-dimensional Petri dish and three-dimensional hydrated collagen gel cultures, a low concentration of TGF- $\beta 1$ amplified the stimulating effect of basic fibroblast growth factor. TGF- $\beta 1$ also promoted the proliferation of ECs in the disc angiogenesis system (Gajdusek et al., 1993). To explore the effect of endogenic TGF- $\beta$ on spontaneous vascular growth of wound healing, the application of an anti-TGF- $\beta$ antibody suppressed the spontaneous angiogenesis lower than the control group (Fajardo et al., 1996). Therefore, endogenous TGF- $\beta$ exerts the effect of promoting spontaneous angiogenesis. Additionally, deficiency of the different components of TGF- $\beta$ signaling has verified that TGF- $\beta$ is essential for angiogenesis, and TGF- $\beta$ receptor mutations are associated with a vascular disease called hereditary hemorrhagic telangiectasia (Bertolino et al., 2005). What is more, in ischemic rat brain following MCAO, leucine-rich $\alpha 2$-glycoprotein 1 (LRG1) may protect the rat brain tissue from ischemic attack through accelerating angiogenesis via upregulating the TGF- $\beta 1$ pathway (Meng et al., 2016). It has been suggested that there is a complex interaction between VEGF and TGF- $\beta 1$, both of which promote angiogenesis but have opposite effects on ECs. VEGF protects ECs against apoptosis, whereas TGF- $\beta 1$ induces apoptosis. Moreover, the suppression of VEGF inhibited both the angiogenesis and apoptosis induced by TGF$\beta 1$, suggesting a refined regulation of angiogenesis through the interaction of these growth factors (Ferrari et al., 2009). In the injured brain, the application of TGF- $\beta$ distinctly facilitated the re-elongation of axons in the injured site in a concentrationdependent manner, suggesting that TGF- $\beta 1$ can also facilitate axonal regeneration of injured brain neuronal cells (Abe et al., 1996).

\section{GM-CSF/G-CSF}

GM-CSF is known to stimulate the growth and polarization of granulocytes and macrophages, exerting a crucial effect in the regulation of innate and adaptive immunity (Seledtsov et al., 2019). As a potent survival factor for monocytes/macrophages, GM-CSF may promote arterial formation in patients with 
cerebral ischemia to enhance their collateral capacity, thereby reducing the brain infarction risk (Lee et al., 2005; Maurer et al., 2008). A previous clinical trial has shown that GMCSF has a positive effect on the therapeutic enhancement of angiogenesis in a group of patients with coronary artery disease (Werner, 2002). Previous research results of GM-CSF subcutaneous injection in hypoperfused rat brain showed that: (1) GM-CSF induced an enlargement of posterior cerebral artery caliber on three-vessel occlusion (3-VO, a non-lethal brain hypoperfusion model); (2) morphological and functional changes could be caused by subcutaneous GM-CSF treatment; (3) GMCSF improved the cerebral hemodynamic parameters on 3-VO, such as $\mathrm{CO}_{2}$ reactivity; and (4) GM-CSF enhanced the infiltration of monocytes/macrophages in the area of vascular collateral formation (Buschmann et al., 2003). These facts indicate that GM-CSF treatment can induce arteriogenesis in hypoperfused rat brain.

G-CSF activates the survival, multiplication, and maturation of cells in the neutrophil lineage (Malashchenko et al., 2018). It is also a neuroprotective cytokine and has a positive effect on angiogenesis and neurogenesis after IS. G-CSF plays a role in regulating the $\mathrm{PI} 3 \mathrm{~K} / \mathrm{AKT}$ signaling pathway, affecting cell proliferation and apoptosis and inducing VEGF expression (Liang et al., 2018). G-CSF increases EC multiplication, the vasal branch points, the vascular surface area, and the length of blood vessels in the ischemic penumbra region (Lee et al., 2005). In addition, the neuroprotective action of G-CSF may be confirmed from all the decreases of the infarct size, the inflammatory infiltration, the $\mathrm{BBB}$ disruption, and the hemispheric atrophy after G-CSF treatment (Menzie-Suderam et al., 2020; Modi et al., 2020). Two possible molecular mechanisms deserve to be considered in angiogenesis induced by G-CSF: (1) the direct activation of cerebral ECs (Liang et al., 2018) and (2) the transference of bone marrow endothelial progenitor cells (EPCs) to the ischemic penumbra area. GCSF was confirmed to stimulate ECs in order to initiate an activation/differentiation procedure, including multiplication and migration, associated with angiogenesis (Bussolino et al., 1991). Moreover, evidences demonstrate that G-CSF increases the expression of angiopoietin-2 (Ang2) and endothelial nitric oxide synthase (eNOS) in the ischemic penumbra of the cerebral cortex (Lee et al., 2005). eNOS is known to be essential to increasing both angiogenesis and the number of circulating EPCs (Endres et al., 2004), while Ang2 has been shown to promote a rapid proliferation of capillary diameter, the basal lamina reestablishment, and the development of new vessels (Ramsauer and D’Amore, 2002).

\section{FGF}

Presently, the FGF family is known to contain more than 20 factors. FGFs are secreted by ECs and are presented in the ectocytic matrix. FGFs are affected by different factors in different tissues. The members of the FGF family exert critical roles in angiogenesis for new blood vessel formation, which dramatically affects the proliferation, mobilization, metastasis, and mobilization of vascular ECs (Chen M. et al., 2020). In particular, FGF-1 (acidic FGF) and FGF-2 (basic FGF) have been verified to affect the modeling of new vessels in some tissues in vivo by regulating ECs (Zhou et al., 2009; Oladipupo et al., 2014). Moreover, FGF-1 and FGF-2 may restrain endothelial-dependent monocyte recruitment and thus have an anti-inflammatory function during angiogenesis in chronic inflammation (Zhang and Issekutz, 2002). Previous researches have illustrated that FGF-1 can initiate angiogenesis and neurogenesis in rats following IS (Cheng et al., 2011) and protect hippocampal neuronal cells against apoptosis induced by IS (Cuevas et al., 1998). Additionally, in mice after IS and human brain microvascular ECs after oxygenglucose deprivation (OGD), non-mitogenic FGF-1 enhanced angiogenesis through regulating sphingosine-1-phosphate 1 (S1P1) signaling mediated by the activation of FGF receptor 1 (FGFR1) (Zou et al., 2020). FGF-2 also plays crucial roles in neurogenesis, angiogenesis, and neuronal survival as well as BBB protection. The expression of FGF-2 in the ischemic penumbra zone of all patients was distinctly increased compared with the infarcted tissue and normal contralateral hemisphere (Issa et al., 2005). Upregulated FGF-2 expression was observed to enhance endogenous neovascularization and hemodynamic changes in the infarct region and to upregulate the number of neuroblast cells migrating toward the ischemic striatum (Oyamada et al., 2008). Moreover, the function of promoting angiogenesis and $\mathrm{BBB}$ protection effect as well as the neuroprotective function of FGF-2 are partially via relieving the OGD/R-induced reduction of S1P1 receptor 1 (S1PR1) (Lin et al., 2018), binding of FGFR1 and activating the ERK signaling pathway (Chen P. et al., 2020), and regulating via the PI3K-AKT-Rac1 pathway (Wang et al., 2016).

\section{HGF}

HGF is a multifunctional growth factor that plays critical roles in mitogenesis, morphogenesis, motogenesis, anti-apoptosis, and angiogenesis. In the brain, HGF functions as an angiogenic factor and a neurotrophic factor. In addition, HGF exhibits neuroprotective actions on ischemia-induced damage through promoting angiogenesis, neurogenesis, and synaptogenesis and inhibiting fibrotic change (Shang et al., 2011). The application of dental pulp stem cells overexpressing HGF in the acute stage of stroke enhanced their neuroprotective actions through regulating inflammation and BBB permeability, thereby mitigating cerebral ischemia-reperfusion injury (CIRI) (Sowa et al., 2018). HGF may also be involved in the prognosis of acute IS at 3 months (Zhu et al., 2018).

\section{PDGF}

The PDGF family is composed of four elements: PDGFA, PDGF-B, PDGF-C, and PDGF-D. PDGF is known to be angiogenic and neuroprotective in IS where PDGFR- $\alpha$ activation in circumvascular astrocyte cells is involved in the acute opening of the BBB. Evidence shows that PDGF-B and its receptor on microvessel ECs may be involved in angiogenesis following IS (Krupinski et al., 1997). Deficiency of either PDGF-B or PDGFR$\beta$ is closely related to characteristics of vascular rupture, including vascular dysfunction, pericyte defects, and the formation of microaneurysms (Gaengel et al., 2009). PDGFR- $\beta$ expression is low in adult normal matured brain. However, its expression 
gradually increases mainly in pericytes and fibroblast-like cells in the ischemic penumbra zone after IS. PDGFR- $\beta$ mediates a variety of functions, including the modulation of the BBB and the rescue of infarcted tissues after IS (Nakamura et al., 2016). Moreover, a current study has shown critical actions of PDGF-C and PDGF-D in neovascularization, fibrosis, atherosclerosis, and restenosis (Folestad et al., 2018).

\section{Interleukins}

IL-1

IL-1 is known to be a primary mediator of central and peripheral inflammation after IS, primarily via the action of both of its subtypes, IL- $1 \alpha$ and IL- $1 \beta$, at cerebral ECs. Previous preclinical studies have demonstrated the deleterious actions of IL-1 following IS, while blocking its actions is salutary in preclinical and clinical settings. However, the pro-inflammatory cytokine IL-1 $\alpha$ was found to increase the brain EC activation, migration, and the proliferation of ECs and to induce chemokine (C-X-C motif) ligand 1 (CXCL-1) and IL-6 (recognized to have angiogenic effects in cerebral ECs) expression as well as promote the construction of capillary tube-like structures in cerebral ECs in vitro (Salmeron et al., 2016). Hence, these findings demonstrate that IL- $1 \alpha$ has angiogenic effects in post-stroke angiogenesis. After ischemia injury, oligodendrocytes respond to inflammatory IL- $1 \beta$ signaling and produce MMP-9 to enhance angiogenesis (Pham et al., 2012).

\section{IL-4}

As an important anti-inflammatory cytokine, IL-4 induces mononuclear/macrophages to differentiate into M2 macrophages through its receptor IL-4R and then secretes more antiinflammatory factors such as IL-10 and TGF- $\beta$, while inhibiting the formation of M1 macrophages and the release of TNF- $\alpha$ and IL-1 (Bhattacharjee et al., 2013). M2 macrophages are known to promote angiogenesis after IS, partially through regulating the HIF1- $\alpha /$ VEGF/NO signaling pathway. Evidence shows that the blockade of IL-4 abrogates the promoting role of hyperforin in post-stroke angiogenesis, neuronal regeneration, and functional rehabilitation (Yao et al., 2019).

\section{IL-6}

Four weeks after MCAO, IL-6 knockout mice displayed a distinctly elevated chronic lesion size and showed a damaged angiogenic response to cerebral ischemia with the reduction of neonatal EC numbers, perfused microvessel density, absolute focal cerebral blood flow, and vessel responsivity in ischemic striatum. These findings suggest that IL-6 plays an important role in angiogenesis after IS. Moreover, resident cerebral cells are the main sources of elevated levels of IL- 6 in the earlyphase post-stroke. IL-6 stimulates the phosphorylation of signal transducer and activator of transcription 3 (STAT3) and the early transcriptional activation of angiogenesis relative genes, thereby leading to the enhanced angiogenesis and increased brain blood flow in the delayed phase after IS (Gertz et al., 2012). IL-6R simultaneously activates the PI3K/AKT and Janus kinase (JAK)/STAT signaling pathways (Xu et al., 2005), which play vital roles in angiogenesis after stroke.

\section{THE ROLE OF INFLAMMATION-RELATIVE SIGNALING PATHWAYS IN POST-STROKE ANGIOGENESIS}

\section{JAK2/STAT3 Pathway}

STAT3 is known to be a key regulator of various inflammatory signals. STAT3 is phosphorylated by phospho-JAK2 (p-JAK2) and is subsequently transferred into the nucleus to regulate the expression of particular genes. Numerous evidences have shown that JAK2/STAT3 signaling activation plays a protective effect against CIRI (Hoffmann et al., 2015; Li et al., 2017). As a direct transcriptional activator of VEGF under hypoxia conditions, STAT3 has recently been confirmed to regulate post-stroke angiogenesis, axon growth, and extracellular matrix remodeling (Hoffmann et al., 2015). Moreover, deficiency of STAT3 signaling is involved in the inhibition of pancreatic carcinoma and kidney cancer through suppressing cancerous angiogenesis (Li et al., 2013). The potential molecular mechanism of angiogenesis induced by the JAK2/STAT3 signaling pathway may be the induction of VEGF production and the regulation of Ang-1 and Ang-2 expression (Li et al., 2017) (Figure 1). As is known, Ang-1 promotes the maturity of new blood vessels and Ang-2 is a destabilizing signaling that reverts vessels to a more malleable state. Numerous cytokines and agents can promote STAT3 phosphorylation or directly activate the JAK2/STAT3 signaling pathway, including IL-6, secretoneurin (Shyu et al., 2008), salvianolic acids (Li et al., 2017), catalpol (Dong et al., 2016), ginkgolide K (Chen et al., 2018), etc., exerting an angiogenic action. What is more, the activation of the JAK2/STAT3 signaling pathway can shift the microglia toward M2 polarization (Qin et al., 2017), which promotes angiogenesis in IS. Additionally, the STAT3 signaling pathway is essential for HIF- $1 \alpha$ expression regulated by VEGF and PI3K/AKT. The expressions of HIF- $1 \alpha$ and VEGF disappeared after STAT3 was blocked by its inhibitor, such as CPA-7 or STAT3 small interfering RNA (siRNA) (Xu et al., 2005). However, the inhibition of STAT3-dependent autophagy can also promote angiogenesis after IS (Xia et al., 2020).

\section{PI3K/AKT Signaling Pathway}

The PI3K/AKT pathway is known to exert a crucial effect in various physiological conditions such as inflammation, oxidative stress, and apoptosis. The activation of the PI3K/AKT pathway can decrease the expression of inflammatory genes and then maintain the vascular capacity. Furthermore, the PI3K/AKT signaling pathway promotes neuronal survival activation and enhances cell survival after IS (Zhang et al., 2016; Li et al., 2019). Activated AKT can promptly stimulate some molecular signals such as rapamycin (mTOR), which promotes protein synthesis and regulates cytotrophy and energy supply. A previous study has illustrated that the activated PI3K/AKT/mTOR pathway exerts essential actions on the effect of apoptosis and inflammation in the brain (Li et al., 2015).

What is noteworthy is that the $\mathrm{PI} 3 \mathrm{~K} / \mathrm{AKT} / \mathrm{mTOR}$ pathway has been proven to be essential for angiogenesis (Figure 2), including EC survival, migration, and new vessel formation. The activated $\mathrm{PI} 3 \mathrm{~K} / \mathrm{AKT} / \mathrm{mTOR}$ signaling activates its downstream factor 


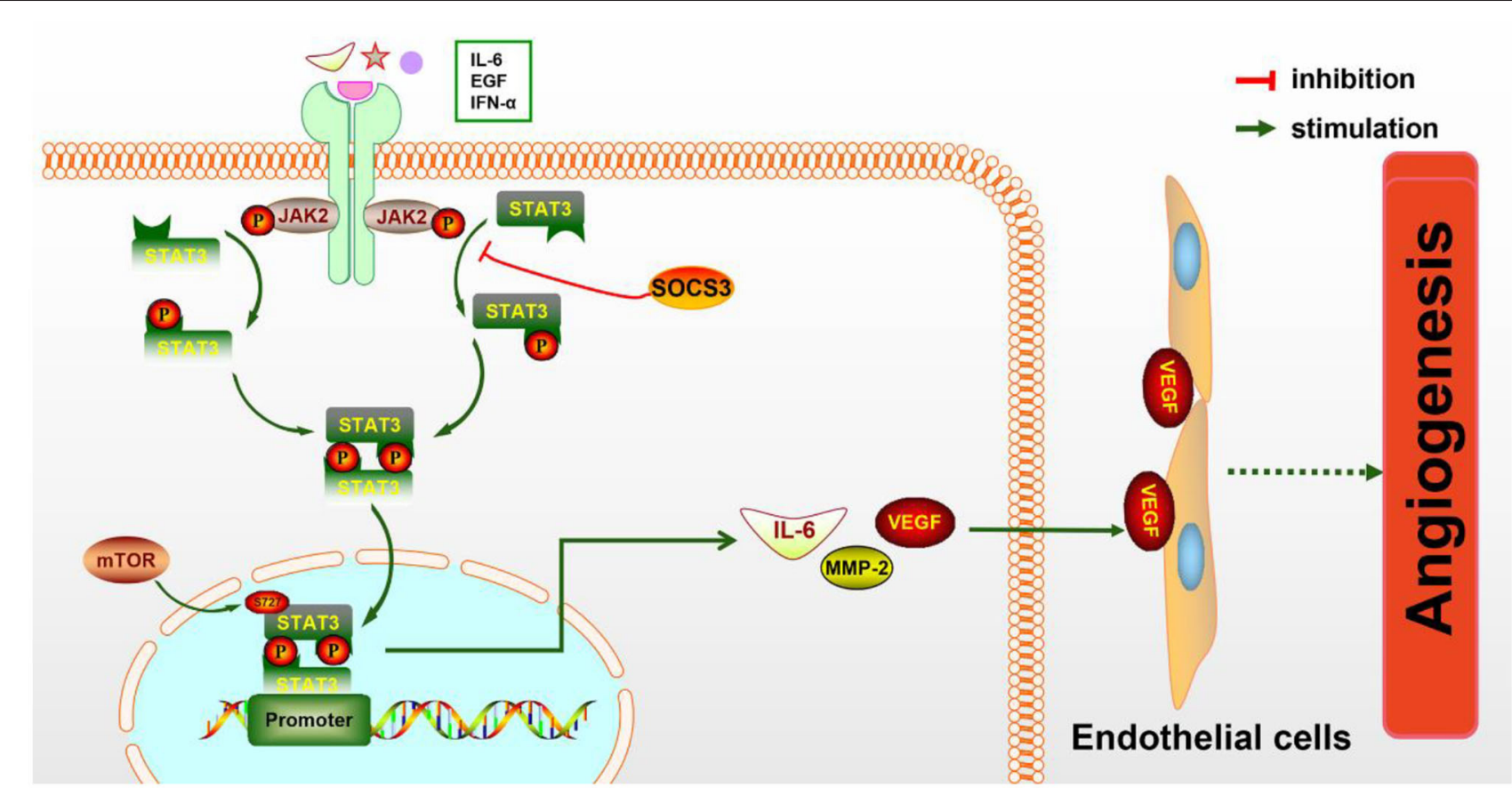

FIGURE 1 | The molecular mechanism of angiogenesis mediated by the JAK2/STAT3 pathway. JAK2 is activated and phosphorylated by inflammatory cytokines such as IL-6 and IFN- $\alpha$, resulting in the phosphorylation of downstream STAT3 and the formation of the p-STAT3 dimer, which is subsequently transferred to the nucleus to promote the expression of particular genes. IL-6, MMP-2, VEGF, and other cytokines are increased, then secreted to the extracellular matrix and act on endothelial cells (ECs), eventually leading to increased angiogenesis.

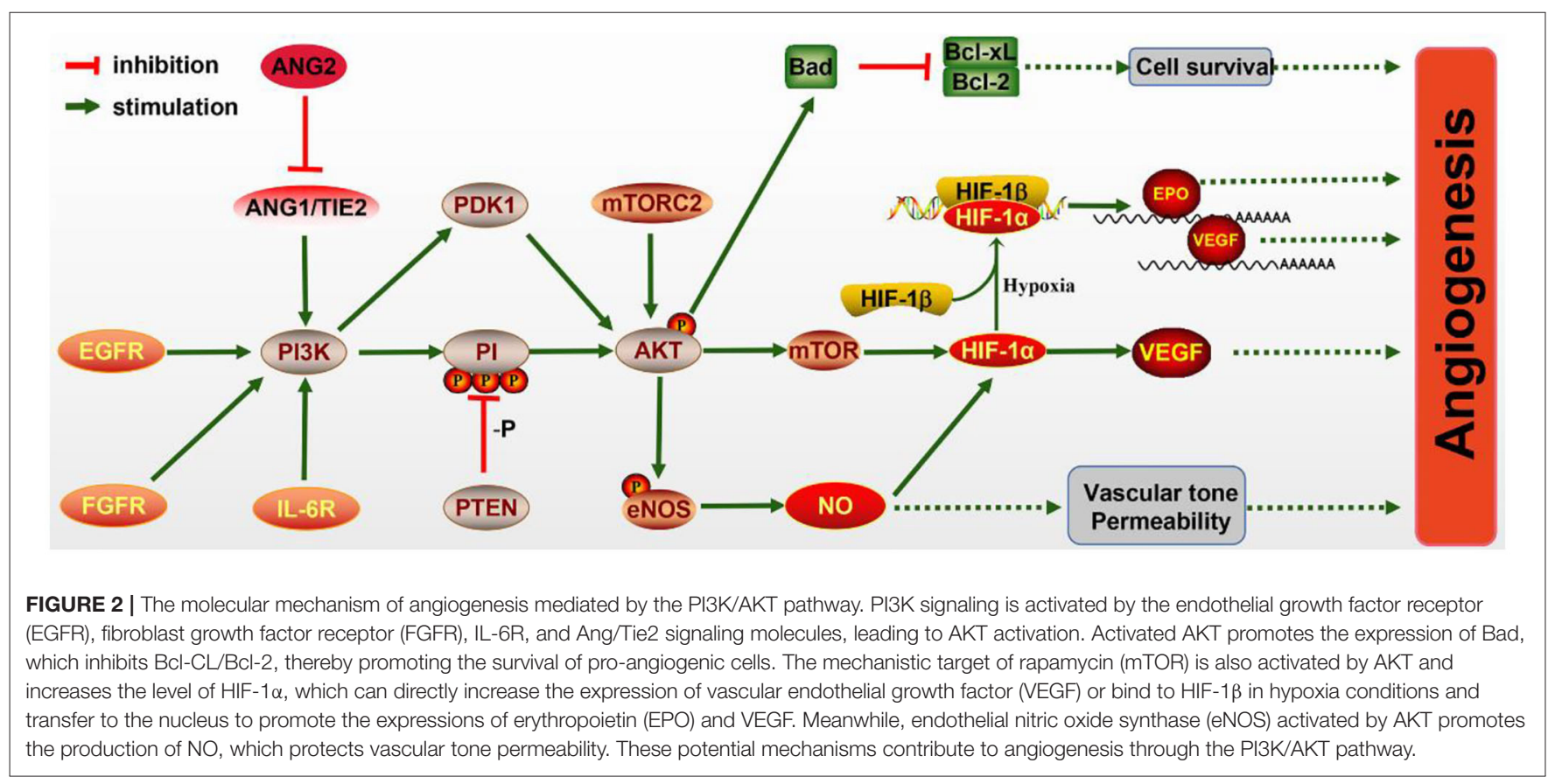

HIF-1 $\alpha$, thereby regulating VEGF expression (Patra et al., 2019), which is known to enhance angiogenesis after IS. In addition, epidermal growth factor (EGF) exerts neuroprotective effects on cerebral ischemia via activating the EGF receptor (EGFR), which also contributes to the activation of the PI3K/AKT/mTOR pathway and elevated HIF-1 $\alpha$ (Karar and Maity, 2011).

In ECs, the PI3K/AKT pathway participates in angiogenesis via regulating nitric oxide $(\mathrm{NO})$ signaling, which is modulated 
by the enzyme NO synthase (NOS). Evidence has illuminated that NO donors can promote the transcriptional activity and expression of HIF-1, thereby inducing the VEGF mRNA (Papapetropoulos et al., 1997). Furthermore, VEGF can initiate NO generation, which is suppressed by the PI3K inhibitor. Hypoxia can also accelerate the phosphorylation of eNOS via activating the PI3K/AKT pathway and HSP9O binding to eNOS. NO production may also be induced via the phosphorylation of eNOS by AKT (Kasuno et al., 2004).

The Ang1/Tie2 system, including the angiopoietins and their receptors, can also activate the PI3K/AKT pathway and promote EC survival. Ang1 and Ang2 bind to Tie2 receptor tyrosine kinase, which is mainly expressed in ECs (Davis et al., 1996; Karar and Maity, 2011). Ang1 is essential for endothelial development, while Ang2 resists the Ang1/Tie2 system and can disrupt vascularization. Research has shown that Ang2 can activate the PI3K/AKT pathway and serve as a stimulant of the Tie2 receptor in the deficiency of Ang1, although weaker than Ang1 (Yuan et al., 2009).

\section{MAPK Pathways}

MAPK pathways amplify, transmit, and integrate signals from a various range of stimuli and induce appropriate physiological reactions including proliferation, differentiation, development, transformation, apoptosis, and inflammatory responses. To date, three MAPK families have been characterized: ERK, p38 MAPK, and c-Jun $\mathrm{N}$-terminal kinase/stress-activated protein kinase (JNK/SAPK). The activation of p38 MAPK/HIF-1 $\alpha /$ VEGF-A exerts anti-apoptotic and angiogenic effects against CIRI (Cheng et al., 2017). The application of MAPK/ERK pathway inhibitors disrupts VEGF-induced angiogenesis, thereby indicating that the MAPK/ERK signaling pathway mediates this process (Pulous et al., 2020). Moreover, hyperbaric oxygen-induced VEGF is activated by C-Jun/ AP- 1 and through simultaneously activating the JNK and ERK signaling pathways (Lee et al., 2006). These findings indicate that ERK, p38 MAPK, and JNK are all involved in regulating angiogenesis in different ways.

\section{NF-кB Signaling Pathway}

$\mathrm{NF}-\kappa \mathrm{B}$, a typical pro-inflammatory signaling molecule, is a key transcriptional factor that plays an important role in the regulation of inflammation, angiogenesis, functional circuit formation, and neurite outgrowth (Cui et al., 2015). The expression of angiogenesis-stimulating factors is partially mediated through the transcriptional activation of NF- $\kappa B$ in response to the inflammatory cytokines IL- $1 \alpha / \beta$ and TNF- $\alpha$ in vascular ECs and monocytes/macrophages, as well as in cancer cells. Inflammatory angiogenesis and the enhanced production of VEGF, in response to IL- $1 \alpha / \beta$ and TNF- $\alpha$, are partially due to the activation of the NF- $\mathrm{kB}$ pathway (Watari et al., 2012). Furthermore, it has been verified that VEGF application activates NF- $\kappa \mathrm{B}$ in vascular ECs. The activation of the NF- $\kappa \mathrm{B}$ signaling pathway is through the activation of the PLC $\gamma$-sphingosine kinase-PKC cascade, resulting in the upregulation of vascular cell adhesion molecule-1 (VCAM-1) and intercellular adhesion molecule-1 (ICAM-1) in monocytes/macrophages or vascular ECs stimulated by VEGF (Kim et al., 2001). In addition, NF-кB is also essential for the stem cell factor (SCF)+G-CSF-induced

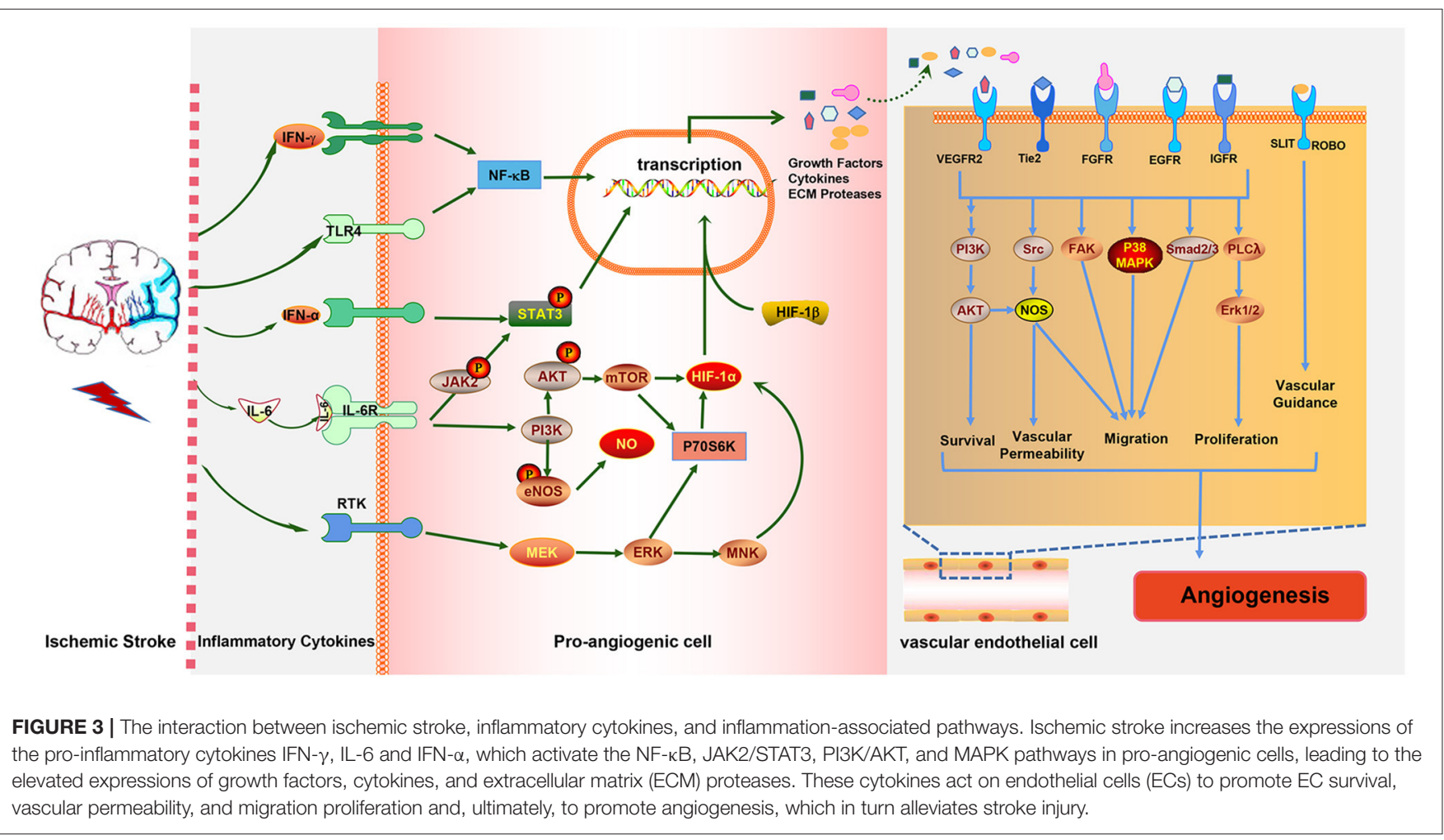


angiogenesis in the ipsilateral somato-sensorimotor cortex after stroke (Cui et al., 2015).

\section{CONCLUSIONS AND PERSPECTIVES}

Numerous studies have repeatedly shown that inflammatory reactions play multiphasic and complex roles in the progression and pathogenesis of IS. As mentioned above, pro-inflammatory cytokines such as IL- $1 \beta$ and TNF- $\alpha$ can promote angiogenesis after IS, but too many pro-inflammatory cytokines have a detrimental effect on the progression of IS. Analogously, anti-inflammatory cytokines such as IL-10 exert a protective effect after stroke, but too many anti-inflammatory factors produce immunosuppression after stroke. Thus, a balance between pro-inflammatory and anti-inflammatory signals is urgently needed to improve IS outcomes.

Various inflammatory cells and inflammatory cytokines, as well as the immune cell subtypes mentioned above, play crucial roles in ischemia-induced angiogenesis. The occurrence of IS induces immune inflammatory responses in brain tissue which can promote angiogenesis. Ultimately, angiogenesis improves stroke prognosis, and eventually, the immune response is mitigated. It is obvious that the three are directly related to each other in a complex way. Moreover, there is also an interaction network between immune cells, inflammatory cytokines, and inflammation-relative signaling pathways involved in post-stroke angiogenesis. For example, IL-6R simultaneously activates the PI3K/AKT and JAK2/STAT3 signaling pathways; in turn, the activation of the JAK2/STAT3 pathway induces the generation

\section{REFERENCES}

Abe, K., Chu, P. J., Ishihara, A., and Saito, H. (1996). Transforming growth factorbeta 1 promotes re-elongation of injured axons of cultured rat hippocampal neurons. Brain Res. 723, 206-209. doi: 10.1016/0006-8993(96)00253-3

Ali, C., Docagne, F., Nicole, O., Lesné, S., Toutain, J., Young, A., et al. (2001). Increased expression of transforming growth factor-beta after cerebral ischemia in the baboon: an endogenous marker of neuronal stress? J. Cereb. Blood Flow Metab. 21, 820-827. doi: 10.1097/00004647-200107000-00007

Armulik, A., Genové, G., and Betsholtz, C. (2011). Pericytes: developmental, physiological, and pathological perspectives, problems, and promises. Dev. Cell 21, 193-215. doi: 10.1016/j.devcel.2011.07.001

Assareh, E., Mehrnejad, F., Mansouri, K., Esmaeili Rastaghi, A. R., Naderi-Manesh, H., and Asghari, S. M. (2019). A cyclic peptide reproducing the $\alpha 1$ helix of VEGF-B binds to VEGFR-1 and VEGFR-2 and inhibits angiogenesis and tumor growth. Biochem. J. 476, 645-663. doi: 10.1042/BCJ20180823

Bell, R. D., Winkler, E. A., Sagare, A. P., Singh, I., LaRue, B., Deane, R., et al. (2010). Pericytes control key neurovascular functions and neuronal phenotype in the adult brain and during brain aging. Neuron 68, 409-427. doi: 10.1016/j.neuron.2010.09.043

Bertolino, P., Deckers, M., Lebrin, F., and ten Dijke, P. (2005). Transforming growth factor-beta signal transduction in angiogenesis and vascular disorders. Chest 128, 585-590. doi: 10.1378/chest.128.6_suppl.585S

Bhattacharjee, A., Shukla, M., Yakubenko, V. P., Mulya, A., Kundu, S., and Cathcart, M. K. (2013). IL-4 and IL-13 employ discrete signaling pathways for target gene expression in alternatively activated monocytes/macrophages. Free Radic. Biol. Med. 54, 1-16. doi: 10.1016/j.freeradbiomed.2012.10.553

Buschmann, I. R., Busch, H. J., Mies, G., and Hossmann, K. A. (2003). Therapeutic induction of arteriogenesis in hypoperfused rat brain via granulocyte-macrophage colony-stimulating factor. Circulation 108, 610-615. doi: 10.1161/01.CIR.0000074209.17561.99 of IL-6 (Figure 3). The STAT3 signaling pathway is also essential for the expression of HIF- $1 \alpha$ mediated by VEGF and PI3K/AKT, whereas HIF- $1 \alpha$ induced by the PI3K/AKT pathway promotes VEGF expression.

In conclusion, in this paper, we mainly discussed the inflammatory and immune cell subsets as well as the associated signaling pathways that contribute to angiogenesis in IS. The immune cell subsets and inflammatory cells involved in angiogenesis after IS mainly contain microglia/macrophage cells, NK cells, CD4 ${ }^{+} \mathrm{T}$ cells, brain pericytes, ECs, etc. Meanwhile, inflammatory cytokines, such as VEGF, MCP-1/CCL2, TNF- $\alpha$, TGF- $\beta$, GM-CSF/G-CSF, FGF, HGF, PDGF, IL, and HIF- $1 \alpha$, play a critical role in the inflammatory-mediated angiogenesis after IS. Targeting these inflammatory cytokines and immune cells may provide the theoretical basis for potential therapies for IS.

\section{AUTHOR CONTRIBUTIONS}

All the listed authors directly, substantially, and intellectually contributed to the preparation of this manuscript and approved the publication.

\section{FUNDING}

This work was supported by the National Natural Science Foundation of China (Grant no. 81870939 to XX, Grant nos. 81771283 and 82071339 to LG) and the Natural Science Foundation of Hubei Province, China (Grant no. 2019CFB498 to $\mathrm{LG})$.

Bussolino, F., Ziche, M., Wang, J. M., Alessi, D., Morbidelli, L., Cremona, O., et al. (1991). In vitro and in vivo activation of endothelial cells by colony-stimulating factors. J. Clin. Invest. 87, 986-995. doi: 10.1172/JCI115107

Candelario-Jalil, E., Yang, Y., and Rosenberg, G. A. (2009). Diverse roles of matrix metalloproteinases and tissue inhibitors of metalloproteinases in neuroinflammation and cerebral ischemia. Neuroscience 158, 983-994. doi: 10.1016/j.neuroscience.2008.06.025

Carmeliet, P. (2003). Angiogenesis in health and disease. Nat. Med. 9, 653-660. doi: 10.1038/nm0603-653

Carmeliet, P., and Collen, D. (2000). Molecular basis of angiogenesis. Role of VEGF and VE-cadherin. Ann. N. Y. Acad. Sci. 902, 249-262; discussion 262-244. doi: 10.1111/j.1749-6632.2000.tb06320.x

Chen, C., Ai, Q. D., Chu, S. F., Zhang, Z., and Chen, N. H. (2019). NK cells in cerebral ischemia. Biomed. Pharmacother. 109, 547-554. doi: 10.1016/j.biopha.2018.10.103

Chen, M., Bao, L., Zhao, M., Cao, J., and Zheng, H. (2020). Progress in research on the role of FGF in the formation and treatment of corneal neovascularization. Front. Pharmacol. 11:111. doi: 10.3389/fphar.2020. 00111

Chen, M., Zou, W., Chen, M., Cao, L., Ding, J., Xiao, W., et al. (2018). Ginkgolide $\mathrm{K}$ promotes angiogenesis in a middle cerebral artery occlusion mouse model via activating JAK2/STAT3 pathway. Eur. J. Pharmacol. 833, 221-229. doi: 10.1016/j.ejphar.2018.06.012

Chen, P., Tang, H., Zhang, Q., Xu, L., Zhou, W., Hu, X., et al. (2020). Basic fibroblast growth factor (bFGF) protects the blood-brain barrier by binding of FGFR1 and activating the ERK signaling pathway after intra-abdominal hypertension and traumatic brain injury. Med. Sci. Monit. 26:e922009. doi: 10.12659/MSM.922009

Cheng, C. Y., Ho, T. Y., Hsiang, C. Y., Tang, N. Y., Hsieh, C. L., Kao, S. T., et al. (2017). Angelica sinensis exerts angiogenic and anti-apoptotic effects against cerebral ischemia-reperfusion injury by activating p38MAPK/HIF-1[Formula: 
see text]/VEGF-A signaling in rats. Am. J. Chin. Med. 45, 1683-1708. doi: 10.1142/S0192415X17500914

Cheng, X., Wang, Z., Yang, J., Ma, M., Lu, T., Xu, G., et al. (2011). Acidic fibroblast growth factor delivered intranasally induces neurogenesis and angiogenesis in rats after ischemic stroke. Neurol. Res. 33, 675-680. doi: 10.1179/1743132810Y.0000000004

Cuevas, P., Carceller, F., Reimers, D., Saenz de Tejada, I., and Giménez-Gallego, G. (1998). Acidic fibroblast growth factor rescues gerbil hippocampal neurons from ischemic apoptotic death. Neurol. Res. 20, 271-274. doi: 10.1080/01616412.1998.11740518

Cui, L., Duchamp, N. S., Boston, D. J., Ren, X., Zhang, X., Hu, H., et al. (2015). NF-кB is involved in brain repair by stem cell factor and granulocytecolony stimulating factor in chronic stroke. Exp. Neurol. 263, 17-27. doi: 10.1016/j.expneurol.2014.08.026

Davis, S., Aldrich, T. H., Jones, P. F., Acheson, A., Compton, D. L., Jain, V., et al. (1996). Isolation of angiopoietin-1, a ligand for the TIE2 receptor, by secretion-trap expression cloning. Cell 87, 1161-1169. doi: 10.1016/S0092-8674(00)81812-7

del Zoppo, G. J., and Mabuchi, T. (2003). Cerebral microvessel responses to focal ischemia. J. Cereb. Blood Flow Metab. 23, 879-894. doi: 10.1097/01.WCB.0000078322.96027.78

Dobolyi, A., Vincze, C., Pál, G., and Lovas, G. (2012). The neuroprotective functions of transforming growth factor beta proteins. Int. J. Mol. Sci. 13, 8219-8258. doi: 10.3390/ijms13078219

Dong, W., Xian, Y., Yuan, W., Huifeng, Z., Tao, W., Zhiqiang, L., et al. (2016). Catalpol stimulates VEGF production via the JAK2/STAT3 pathway to improve angiogenesis in rats' stroke model. J. Ethnopharmacol. 191, 169-179. doi: 10.1016/j.jep.2016.06.030

Doyle, K. P., Cekanaviciute, E., Mamer, L. E., and Buckwalter, M. S. (2010). TGF $\beta$ signaling in the brain increases with aging and signals to astrocytes and innate immune cells in the weeks after stroke. J. Neuroinflammation 7:62. doi: 10.1186/1742-2094-7-62

Eilken, H. M., and Adams, R. H. (2010). Dynamics of endothelial cell behavior in sprouting angiogenesis. Curr. Opin. Cell Biol. 22, 617-625. doi: 10.1016/j.ceb.2010.08.010

Endres, M., Laufs, U., Liao, J. K., and Moskowitz, M. A. (2004). Targeting eNOS for stroke protection. Trends Neurosci. 27, 283-289. doi: 10.1016/j.tins.2004.03.009

Ergün, S., Kilic, N., Wurmbach, J. H., Ebrahimnejad, A., Fernando, M., Sevinc, S., et al. (2001). Endostatin inhibits angiogenesis by stabilization of newly formed endothelial tubes. Angiogenesis 4, 193-206. doi: 10.1023/A:1014027218980

Fajardo, L. F., Prionas, S. D., Kwan, H. H., Kowalski, J., and Allison, A. C. (1996). Transforming growth factor beta1 induces angiogenesis in vivo with a threshold pattern. Lab. Invest. 74, 600-608.

Ferrari, G., Cook, B. D., Terushkin, V., Pintucci, G., and Mignatti, P. (2009). Transforming growth factor-beta 1 (TGF-beta1) induces angiogenesis through vascular endothelial growth factor (VEGF)-mediated apoptosis. J. Cell. Physiol. 219, 449-458. doi: 10.1002/jcp.21706

Folestad, E., Kunath, A., and Wågsäter, D. (2018). PDGF-C and PDGF-D signaling in vascular diseases and animal models. Mol. Aspects Med. 62, 1-11. doi: 10.1016/j.mam.2018.01.005

Franco, M., Roswall, P., Cortez, E., Hanahan, D., and Pietras, K. (2011). Pericytes promote endothelial cell survival through induction of autocrine VEGF-A signaling and Bcl-w expression. Blood 118, 2906-2917. doi: 10.1182/blood-2011-01-331694

Gaengel, K., Genové, G., Armulik, A., and Betsholtz, C. (2009). Endothelial-mural cell signaling in vascular development and angiogenesis. Arterioscler. Thromb. Vasc. Biol. 29, 630-638. doi: 10.1161/ATVBAHA.107.161521

Gajdusek, C. M., Luo, Z., and Mayberg, M. R. (1993). Basic fibroblast growth factor and transforming growth factor beta-1: synergistic mediators of angiogenesis in vitro. J. Cell. Physiol. 157, 133-144. doi: 10.1002/jcp.1041570118

Gertz, K., Kronenberg, G., Kälin, R. E., Baldinger, T., Werner, C., Balkaya, M., et al. (2012). Essential role of interleukin-6 in post-stroke angiogenesis. Brain 135, 1964-1980. doi: 10.1093/brain/aws075

Greenberg, D. A., and Jin, K. (2005). From angiogenesis to neuropathology. Nature 438, 954-959. doi: 10.1038/nature04481

Hayashi, T., Noshita, N., Sugawara, T., and Chan, P. H. (2003). Temporal profile of angiogenesis and expression of related genes in the brain after ischemia. J. Cereb. Blood Flow Metab. 23, 166-180. doi: 10.1097/01.WCB.0000041283.53351.CB

Herz, J., Reitmeir, R., Hagen, S. I., Reinboth, B. S., Guo, Z., Zechariah, A., et al. (2012). Intracerebroventricularly delivered VEGF promotes contralesional corticorubral plasticity after focal cerebral ischemia via mechanisms involving anti-inflammatory actions. Neurobiol. Dis. 45, 1077-1085. doi: 10.1016/j.nbd.2011.12.026

Hinojosa, A. E., Garcia-Bueno, B., Leza, J. C., and Madrigal, J. L. (2011). CCL2/MCP-1 modulation of microglial activation and proliferation. J. Neuroinflammation 8:77. doi: 10.1186/1742-2094-8-77

Hoffmann, C. J., Harms, U., Rex, A., Szulzewsky, F., Wolf, S. A., Grittner, U., et al. (2015). Vascular signal transducer and activator of transcription-3 promotes angiogenesis and neuroplasticity long-term after stroke. Circulation 131, 1772-1782. doi: 10.1161/CIRCULATIONAHA.114.013003

Hong, K. H., Ryu, J., and Han, K. H. (2005). Monocyte chemoattractant protein1 -induced angiogenesis is mediated by vascular endothelial growth factor-A. Blood 105, 1405-1407. doi: 10.1182/blood-2004-08-3178

Huang, H., Huang, Q., Wang, F., Milner, R., and Li, L. (2016). Cerebral ischemiainduced angiogenesis is dependent on tumor necrosis factor receptor 1mediated upregulation of $\alpha 5 \beta 1$ and $\alpha \mathrm{V} \beta 3$ integrins. J. Neuroinflammation 13:227. doi: 10.1186/s12974-016-0697-1

Ishitsuka, K., Ago, T., Arimura, K., Nakamura, K., Tokami, H., Makihara, N., et al. (2012). Neurotrophin production in brain pericytes during hypoxia: a role of pericytes for neuroprotection. Microvasc. Res. 83, 352-359. doi: 10.1016/j.mvr.2012.02.009

Issa, R., AlQteishat, A., Mitsios, N., Saka, M., Krupinski, J., Tarkowski, E., et al. (2005). Expression of basic fibroblast growth factor mRNA and protein in the human brain following ischaemic stroke. Angiogenesis 8, 53-62. doi: 10.1007/s10456-005-5613-8

Jain, R. K. (2003). Molecular regulation of vessel maturation. Nat. Med. 9, 685-693. doi: 10.1038/nm0603-685

Jakobsson, L., Franco, C. A., Bentley, K., Collins, R. T., Ponsioen, B., Aspalter, I. M., et al. (2010). Endothelial cells dynamically compete for the tip cell position during angiogenic sprouting. Nat. Cell Biol. 12, 943-953. doi: 10.1038/ncb2103

Jetten, N., Verbruggen, S., Gijbels, M. J., Post, M. J., De Winther, M. P., and Donners, M. M. (2014). Anti-inflammatory M2, but not pro-inflammatory M1 macrophages promote angiogenesis in vivo. Angiogenesis 17, 109-118. doi: 10.1007/s10456-013-9381-6

Kaiser, D., Weise, G., Möller, K., Scheibe, J., Pösel, C., Baasch, S., et al. (2014). Spontaneous white matter damage, cognitive decline and neuroinflammation in middle-aged hypertensive rats: an animal model of early-stage cerebral small vessel disease. Acta Neuropathol. Commun. 2:169. doi: 10.1186/s40478-014-0169-8

Karar, J., and Maity, A. (2011). PI3K/AKT/mTOR pathway in angiogenesis. Front. Mol. Neurosci. 4:51. doi: 10.3389/fnmol.2011.00051

Kariya, T., Nishimura, H., Mizuno, M., Suzuki, Y., Matsukawa, Y., Sakata, F., et al. (2018). TGF- $\beta 1$-VEGF-A pathway induces neoangiogenesis with peritoneal fibrosis in patients undergoing peritoneal dialysis. Am. J. Physiol. Renal Physiol. 314, 167-180. doi: 10.1152/ajprenal.00052.2017

Kasuno, K., Takabuchi, S., Fukuda, K., Kizaka-Kondoh, S., Yodoi, J., Adachi, T., et al. (2004). Nitric oxide induces hypoxia-inducible factor 1 activation that is dependent on MAPK and phosphatidylinositol 3-kinase signaling. J. Biol. Chem. 279, 2550-2558. doi: 10.1074/jbc.M308197200

Kilic, E., Kilic, U., Wang, Y., Bassetti, C. L., Marti, H. H., and Hermann, D. M. (2006). The phosphatidylinositol-3 kinase/Akt pathway mediates VEGF's neuroprotective activity and induces blood brain barrier permeability after focal cerebral ischemia. FASEB J. 20, 1185-1187. doi: 10.1096/fj.05-4829fje

Kim, I., Moon, S. O., Kim, S. H., Kim, H. J., Koh, Y. S., and Koh, G. Y. (2001). Vascular endothelial growth factor expression of intercellular adhesion molecule 1 (ICAM-1), vascular cell adhesion molecule 1 (VCAM-1), and E-selectin through nuclear factor-kappa B activation in endothelial cells. J. Biol. Chem. 276, 7614-7620. doi: 10.1074/jbc.M0097 05200

Kim, J. J., Kim, D. H., Lee, J. Y., Lee, B. C., Kang, I., Kook, M. G., et al. (2020). cAMP/EPAC signaling enables ETV2 to induce endothelial cells with high angiogenesis potential. Mol. Ther. 28, 466-478. doi: 10.1016/j.ymthe.2019.11.019 
Kossmann, S., Schwenk, M., Hausding, M., Karbach, S. H., Schmidgen, M. I., Brandt, M., et al. (2013). Angiotensin II-induced vascular dysfunction depends on interferon- $\gamma$-driven immune cell recruitment and mutual activation of monocytes and NK-cells. Arterioscler. Thromb. Vasc. Biol. 33, 1313-1319. doi: 10.1161/ATVBAHA.113.301437

Krupinski, J., Issa, R., Bujny, T., Slevin, M., Kumar, P., Kumar, S., et al. (1997). A putative role for platelet-derived growth factor in angiogenesis and neuroprotection after ischemic stroke in humans. Stroke 28, 564-573. doi: 10.1161/01.STR.28.3.564

Krupinski, J., Kaluza, J., Kumar, P., Kumar, S., and Wang, J. M. (1994). Role of angiogenesis in patients with cerebral ischemic stroke. Stroke 25, 1794-1798. doi: 10.1161/01.STR.25.9.1794

Krupinski, J., Kumar, P., Kumar, S., and Kaluza, J. (1996). Increased expression of TGF-beta 1 in brain tissue after ischemic stroke in humans. Stroke 27, 852-857. doi: 10.1161/01.STR.27.5.852

Kume, T. (2012). Ligand-dependent Notch signaling in vascular formation. $A d v$. Exp. Med. Biol. 727, 210-222. doi: 10.1007/978-1-4614-0899-4_16

Kwee, B. J., Budina, E., Najibi, A. J., and Mooney, D. J. (2018). CD4 Tcells regulate angiogenesis and myogenesis. Biomaterials 178, 109-121. doi: 10.1016/j.biomaterials.2018.06.003

la Sala, A., Pontecorvo, L., Agresta, A., Rosano, G., and Stabile, E. (2012). Regulation of collateral blood vessel development by the innate and adaptive immune system. Trends Mol. Med. 18, 494-501. doi: 10.1016/j.molmed.2012.06.007

Lanahan, A. A., Hermans, K., Claes, F., Kerley-Hamilton, J. S., Zhuang, Z. W., Giordano, F. J., et al. (2010). VEGF receptor 2 endocytic trafficking regulates arterial morphogenesis. Dev. Cell. 18, 713-724. doi: 10.1016/j.devcel.2010.02.016

Lee, C. C., Chen, S. C., Tsai, S. C., Wang, B. W., Liu, Y. C., Lee, H. M., et al. (2006). Hyperbaric oxygen induces VEGF expression through ERK, JNK and c-Jun/AP-1 activation in human umbilical vein endothelial cells. J. Biomed. Sci. 13, 143-156. doi: 10.1007/s11373-005-9037-7

Lee, S., Chen, T. T., Barber, C. L., Jordan, M. C., Murdock, J., Desai, S., et al. (2007). Autocrine VEGF signaling is required for vascular homeostasis. Cell 130, 691-703. doi: 10.1016/j.cell.2007.06.054

Lee, S., Kim, O. J., Lee, K. O., Jung, H., Oh, S. H., and Kim, N. K. (2020). Enhancing the therapeutic potential of CCL2-overexpressing mesenchymal stem cells in acute stroke. Int. J. Mol. Sci. 21:7795. doi: 10.3390/ijms21207795

Lee, S. T., Chu, K., Jung, K. H., Ko, S. Y., Kim, E. H., Sinn, D. I., et al. (2005). Granulocyte colony-stimulating factor enhances angiogenesis after focal cerebral ischemia. Brain Res. 1058, 120-128. doi: 10.1016/j.brainres.2005.07.076

Lehrmann, E., Kiefer, R., Christensen, T., Toyka, K. V., Zimmer, J., Diemer, N. H., et al. (1998). Microglia and macrophages are major sources of locally produced transforming growth factor-betal after transient middle cerebral artery occlusion in rats. Glia 24, 437-448. doi: 10.1002/(SICI)10981136(199812)24:4<437::AID-GLIA9>3.0.CO;2-X

Lenzlinger, P. M., Morganti-Kossmann, M. C., Laurer, H. L., and McIntosh, T. K. (2001). The duality of the inflammatory response to traumatic brain injury. Mol. Neurobiol. 24, 169-181. doi: 10.1385/MN:24:1-3:169

Li, F., Lan, Y., Wang, Y., Wang, J., Yang, G., Meng, F., et al. (2011). Endothelial Smad4 maintains cerebrovascular integrity by activating N-cadherin through cooperation with Notch. Dev. Cell 20, 291-302. doi: 10.1016/j.devcel.2011.01.011

Li, S., Priceman, S. J., Xin, H., Zhang, W., Deng, J., Liu, Y., et al. (2013). Icaritin inhibits JAK/STAT3 signaling and growth of renal cell carcinoma. PLoS ONE 8:e81657. doi: 10.1371/journal.pone.0081657

Li, T. F., Ma, J., Han, X. W., Jia, Y. X., Yuan, H. F., Shui, S. F., et al. (2019). Chrysin ameliorates cerebral ischemia/reperfusion (I/R) injury in rats by regulating the PI3K/Akt/mTOR pathway. Neurochem. Int. 129:104496. doi: 10.1016/j.neuint.2019.104496

Li, W., Yang, Y., Hu, Z., Ling, S., and Fang, M. (2015). Neuroprotective effects of DAHP and Triptolide in focal cerebral ischemia via apoptosis inhibition and PI3K/Akt/mTOR pathway activation. Front. Neuroanat. 9:48. doi: 10.3389/fnana.2015.00048

Li, Y., Zhang, X., Cui, L., Chen, R., Zhang, Y., Zhang, C., et al. (2017). Salvianolic acids enhance cerebral angiogenesis and neurological recovery by activating JAK2/STAT3 signaling pathway after ischemic stroke in mice. J. Neurochem. 143, 87-99. doi: $10.1111 /$ jnc. 14140
Liang, S. D., Ma, L. Q., Gao, Z. Y., Zhuang, Y. Y., and Zhao, Y. Z. (2018). Granulocyte colony-stimulating factor improves neurological function and angiogenesis in intracerebral hemorrhage rats. Eur. Rev. Med. Pharmacol. Sci. 22, 2005-2014. doi: 10.26355/eurrev_201804_14729

Lin, L., Wang, Q., Qian, K., Cao, Z., Xiao, J., Wang, X., et al. (2018). bFGF protects against oxygen glucose deprivation/reoxygenation-induced endothelial monolayer permeability via S1PR1-dependent mechanisms. Mol. Neurobiol. 55, 3131-3142. doi: 10.1007/s12035-017-0544-0

Liu, T., Clark, R. K., McDonnell, P. C., Young, P. R., White, R. F., Barone, F. C., et al. (1994). Tumor necrosis factor-alpha expression in ischemic neurons. Stroke 25, 1481-1488. doi: 10.1161/01.STR.25.7.1481

Liu, X., Wen, S., Yan, F., Liu, K., Liu, L., Wang, L., et al. (2018). Salidroside provides neuroprotection by modulating microglial polarization after cerebral ischemia. J. Neuroinflammation 15:39. doi: 10.1186/s12974-018-1081-0

Lund, H., Pieber, M., Parsa, R., Grommisch, D., Ewing, E., Kular, L., et al. (2018). Fatal demyelinating disease is induced by monocyte-derived macrophages in the absence of TGF- $\beta$ signaling. Nat. Immunol. 19, 1-7. doi: 10.1038/s41590-018-0091-5

Luo, D., Luo, Y., He, Y., Zhang, H., Zhang, R., Li, X., et al. (2006). Differential functions of tumor necrosis factor receptor 1 and 2 signaling in ischemiamediated arteriogenesis and angiogenesis. Am. J. Pathol. 169, 1886-1898. doi: 10.2353/ajpath.2006.060603

Malashchenko, V. V., Meniailo, M. E., Shmarov, V. A., Gazatova, N. D., Melashchenko, O. B., Goncharov, A. G., et al. (2018). Direct anti-inflammatory effects of granulocyte colony-stimulating factor (G-CSF) on activation and functional properties of human $\mathrm{T}$ cell subpopulations in vitro. Cell. Immunol. 325, 23-32. doi: 10.1016/j.cellimm.2018.01.007

Malik, A. R., Lips, J., Gorniak-Walas, M., Broekaart, D. W. M., Asaro, A., Kuffner, M. T. C., et al. (2020). SorCS2 facilitates release of endostatin from astrocytes and controls post-stroke angiogenesis. Glia 68, 1304-1316. doi: $10.1002 /$ glia.23778

Manoonkitiwongsa, P. S., Jackson-Friedman, C., McMillan, P. J., Schultz, R. L., and Lyden, P. D. (2001). Angiogenesis after stroke is correlated with increased numbers of macrophages: the clean-up hypothesis. J. Cereb. Blood Flow Metab. 21, 1223-1231. doi: 10.1097/00004647-200110000-00011

Marti, H. J., Bernaudin, M., Bellail, A., Schoch, H., Euler, M., Petit, E., et al. (2000). Hypoxia-induced vascular endothelial growth factor expression precedes neovascularization after cerebral ischemia. Am. J. Pathol. 156, 965-976. doi: 10.1016/S0002-9440(10)64964-4

Marumo, T., Schini-Kerth, V. B., and Busse, R. (1999). Vascular endothelial growth factor activates nuclear factor-kappaB and induces monocyte chemoattractant protein-1 in bovine retinal endothelial cells. Diabetes 48, 1131-1137. doi: $10.2337 /$ diabetes.48.5.1131

Maurer, M. H., Schäbitz, W. R., and Schneider, A. (2008). Old friends in new constellations-the hematopoetic growth factors G-CSF, GM-CSF, and EPO for the treatment of neurological diseases. Curr. Med. Chem. 15, 1407-1411. doi: 10.2174/092986708784567671

Meng, H., Song, Y., Zhu, J., Liu, Q., Lu, P., Ye, N., et al. (2016). LRG1 promotes angiogenesis through upregulating the TGF- $\beta 1$ pathway in ischemic rat brain. Mol. Med. Rep. 14, 5535-5543. doi: 10.3892/mmr.2016.5925

Menzie-Suderam, J. M., Modi, J., Xu, H., Bent, A., Trujillo, P., Medley, K., et al. (2020). Granulocyte-colony stimulating factor gene therapy as a novel therapeutics for stroke in a mouse model. J. Biomed. Sci. 27:99. doi: 10.1186/s12929-020-00692-5

Modi, J., Menzie-Suderam, J., Xu, H., Trujillo, P., Medley, K., Marshall, M. L., et al. (2020). Mode of action of granulocyte-colony stimulating factor (GCSF) as a novel therapy for stroke in a mouse model. J. Biomed. Sci. 27:19. doi: 10.1186/s12929-019-0597-7

Muoio, V., Persson, P. B., and Sendeski, M. M. (2014). The neurovascular unit concept review. Acta Physiol. 210, 790-798. doi: 10.1111/apha.12250

Nakamura, K., Arimura, K., Nishimura, A., Tachibana, M., Yoshikawa, Y., Makihara, N., et al. (2016). Possible involvement of basic FGF in the upregulation of PDGFR $\beta$ in pericytes after ischemic stroke. Brain Res. 1630, 98-108. doi: 10.1016/j.brainres.2015.11.003

Nossent, A. Y., Bastiaansen, A. J., Peters, E. A., de Vries, M. R., Aref, Z., Welten, S. M., et al. (2017). CCR7-CCL19/CCL21 axis is essential for effective arteriogenesis in a murine model of hindlimb ischemia. J. Am. Heart Assoc. 6:e005281. doi: 10.1161/JAHA.116.005281 
Oladipupo, S. S., Smith, C., Santeford, A., Park, C., Sene, A., Wiley, L. A., et al. (2014). Endothelial cell FGF signaling is required for injury response but not for vascular homeostasis. Proc. Natl. Acad. Sci. U. S. A. 111, 13379-13384. doi: 10.1073/pnas.1324235111

Olofsson, B., Pajusola, K., von Euler, G., Chilov, D., Alitalo, K., and Eriksson, U. (1996). Genomic organization of the mouse and human genes for vascular endothelial growth factor B (VEGF-B) and characterization of a second splice isoform. J. Biol. Chem. 271, 19310-19317. doi: 10.1074/jbc.271.32.19310

Oyamada, N., Sone, M., Miyashita, K., Park, K., Taura, D., Inuzuka, M., et al. (2008). The role of mineralocorticoid receptor expression in brain remodeling after cerebral ischemia. Endocrinology 149, 3764-3777. doi: 10.1210/en.2007-1770

Pan, J. R., Li, Y., Pei, Z., Li, X. P., Peng, Y., and Wang, Y. D. (2010). Hypoxic tissues are associated with microvessel density following brain ischemia-reperfusion. Neurol. Sci. 31, 765-771. doi: 10.1007/s10072-010-0441-z

Papapetropoulos, A., García-Cardeña, G., Madri, J. A., and Sessa, W. C. (1997). Nitric oxide production contributes to the angiogenic properties of vascular endothelial growth factor in human endothelial cells. J. Clin. Invest. 100, 3131-3139. doi: 10.1172/JCI119868

Patra, K., Jana, S., Sarkar, A., Mandal, D. P., and Bhattacharjee, S. (2019). The inhibition of hypoxia-induced angiogenesis and metastasis by cinnamaldehyde is mediated by decreasing HIF- $1 \alpha$ protein synthesis via PI3K/Akt pathway. Biofactors 45, 401-415. doi: 10.1002/biof.1499

Pham, L. D., Hayakawa, K., Seo, J. H., Nguyen, M. N., Som, A. T., Lee, B. J., et al. (2012). Crosstalk between oligodendrocytes and cerebral endothelium contributes to vascular remodeling after white matter injury. Glia 60, 875-881. doi: $10.1002 /$ glia. 22320

Potente, M., Gerhardt, H., and Carmeliet, P. (2011). Basic and therapeutic aspects of angiogenesis. Cell 146, 873-887. doi: 10.1016/j.cell.2011.08.039

Pulous, F. E., Carnevale, J. C., Al-Yafeai, Z., Pearson, B. H., Hamilton, J. A. G., Henry, C. J., et al. (2020). Talin-dependent integrin activation is required for endothelial proliferation and postnatal angiogenesis. Angiogenesis 24, 177-190. doi: 10.1007/s10456-020-09756-4

Qin, C., Fan, W. H., Liu, Q., Shang, K., Murugan, M., Wu, L. J., et al. (2017). Fingolimod protects against ischemic white matter damage by modulating microglia toward M2 polarization via STAT3 pathway. Stroke 48, 3336-3346. doi: 10.1161/STROKEAHA.117.018505

Ramsauer, M., and D'Amore, P. A. (2002). Getting Tie(2)d up in angiogenesis. J. Clin. Invest. 110, 1615-1617. doi: 10.1172/JCI0217326

Reitmeir, R., Kilic, E., Reinboth, B. S., Guo, Z., ElAli, A., Zechariah, A., et al. (2012). Vascular endothelial growth factor induces contralesional corticobulbar plasticity and functional neurological recovery in the ischemic brain. Acta Neuropathol. 123, 273-284. doi: 10.1007/s00401-011-0914-z

Ribatti, D., Tamma, R., and Crivellato, E. (2019). Cross talk between natural killer cells and mast cells in tumor angiogenesis. Inflamm. Res. 68, 19-23. doi: 10.1007/s00011-018-1181-4

Roberts, A. B., Sporn, M. B., Assoian, R. K., Smith, J. M., Roche, N. S., Wakefield, L. M., et al. (1986). Transforming growth factor type beta: rapid induction of fibrosis and angiogenesis in vivo and stimulation of collagen formation in vitro. Proc. Natl. Acad. Sci. U. S. A. 83, 4167-4171. doi: 10.1073/pnas.83.12.4167

Rustenhoven, J., Jansson, D., Smyth, L. C., and Dragunow, M. (2017). Brain pericytes as mediators of neuroinflammation. Trends Pharmacol. Sci. 38, 291-304. doi: 10.1016/j.tips.2016.12.001

Saha, P., and Smith, A. (2018). TNF- $\alpha$ (Tumor Necrosis Factor- $\alpha$ ). Arterioscler. Thromb. Vasc. Biol. 38, 2542-2543. doi: 10.1161/ATVBAHA.118.311660

Salmeron, K., Aihara, T., Redondo-Castro, E., Pinteaux, E., and Bix, G. (2016). IL-1alpha induces angiogenesis in brain endothelial cells in vitro: implications for brain angiogenesis after acute injury. J. Neurochem. 136, 573-580. doi: $10.1111 /$ jnc. 13422

Saoud, H., Inoubli, O., Ben Fredj, S., Hassine, M., Ben Mohamed, B., Gaha, L., et al. (2019). Protective effect of the MCP-1 gene haplotype against schizophrenia. Biomed. Res. Int. 2019:4042615. doi: 10.1155/2019/40 42615

Schierling, W., Troidl, K., Mueller, C., Troidl, C., Wustrack, H., Bachmann, G., et al. (2009). Increased intravascular flow rate triggers cerebral arteriogenesis. J. Cereb. Blood Flow Metab. 29, 726-737. doi: 10.1038/jcbfm.2008.165

Schmidt, R., Schmidt, H., and Fazekas, F. (2000). Vascular risk factors in dementia. J. Neurol. 247, 81-87. doi: 10.1007/s004150050021
Seledtsov, V. I., Malashchenko, V. V., Gazatova, N. D., Meniailo, M. E., Morozova, E. M., and Seledtsova, G. V. (2019). Directs effects of granulocyte-macrophage colony stimulating factor (GM-CSF) on adaptive immunogenesis. Hum. Vaccin. Immunother. 15, 2903-2909. doi: 10.1080/21645515.2019.1614396

Shang, J., Deguchi, K., Ohta, Y., Liu, N., Zhang, X., Tian, F., et al. (2011). Strong neurogenesis, angiogenesis, synaptogenesis, and antifibrosis of hepatocyte growth factor in rats brain after transient middle cerebral artery occlusion. $J$. Neurosci. Res. 89, 86-95. doi: 10.1002/jnr.22524

Shang, K., He, J., Zou, J., Qin, C., Lin, L., Zhou, L. Q., et al. (2020). Fingolimod promotes angiogenesis and attenuates ischemic brain damage via modulating microglial polarization. Brain Res. 1726:146509. doi: 10.1016/j.brainres.2019.146509

Shyu, W. C., Lin, S. Z., Chiang, M. F., Chen, D. C., Su, C. Y., Wang, H. J., et al. (2008). Secretoneurin promotes neuroprotection and neuronal plasticity via the Jak2/Stat3 pathway in murine models of stroke. J. Clin. Invest. 118, 133-148. doi: $10.1172 /$ JCI32723

Sowa, K., Nito, C., Nakajima, M., Suda, S., Nishiyama, Y., Sakamoto, Y., et al. (2018). Impact of dental pulp stem cells overexpressing hepatocyte growth factor after cerebral ischemia/reperfusion in rats. Mol. Ther. Methods Clin. Dev. 10, 281-290. doi: 10.1016/j.omtm.2018.07.009

Stapor, P. C., Sweat, R. S., Dashti, D. C., Betancourt, A. M., and Murfee, W. L. (2014). Pericyte dynamics during angiogenesis: new insights from new identities. J. Vasc. Res. 51, 163-174. doi: 10.1159/000362276

Stockmann, C., Doedens, A., Weidemann, A., Zhang, N., Takeda, N., Greenberg, J. I., et al. (2008). Deletion of vascular endothelial growth factor in myeloid cells accelerates tumorigenesis. Nature 456, 814-818. doi: 10.1038/nature07445

Sugano, M., Tsuchida, K., and Makino, N. (2004). Intramuscular gene transfer of soluble tumor necrosis factor-alpha receptor 1 activates vascular endothelial growth factor receptor and accelerates angiogenesis in a rat model of hindlimb ischemia. Circulation 109, 797-802. doi: 10.1161/01.CIR.0000112579.61522.67

Takahashi, H., and Shibuya, M. (2005). The vascular endothelial growth factor (VEGF)/VEGF receptor system and its role under physiological and pathological conditions. Clin. Sci. 109, 227-241. doi: 10.1042/CS20040370

Taoufik, E., Petit, E., Divoux, D., Tseveleki, V., Mengozzi, M., Roberts, M. L., et al. (2008). TNF receptor I sensitizes neurons to erythropoietin- and VEGFmediated neuroprotection after ischemic and excitotoxic injury. Proc. Natl. Acad. Sci. U. S. A. 105, 6185-6190. doi: 10.1073/pnas.0801447105

Uemura, M. T., Maki, T., Ihara, M., Lee, V. M. Y., and Trojanowski, J. Q. (2020). Brain microvascular pericytes in vascular cognitive impairment and dementia. Front. Aging Neurosci. 12:80. doi: 10.3389/fnagi.2020.00080

Umehara, K., Sun, Y., Hiura, S., Hamada, K., Itoh, M., Kitamura, K., et al. (2018). A new conditionally immortalized human fetal brain pericyte cell line: establishment and functional characterization as a promising tool for human brain pericyte studies. Mol. Neurobiol. 55, 5993-6006. doi: 10.1007/s12035-017-0815-9

van Weel, V., Toes, R. E., Seghers, L., Deckers, M. M., de Vries, M. R., Eilers, P. H., et al. (2007). Natural killer cells and CD4+ T-cells modulate collateral artery development. Arterioscler. Thromb. Vasc. Biol. 27, 2310-2318. doi: 10.1161/ATVBAHA.107.151407

Vincze, C., Pál, G., Wappler, E. A., Szabó, E. R., Nagy, Z. G., Lovas, G., et al. (2010). Distribution of mRNAs encoding transforming growth factorsbeta $1,-2$, and -3 in the intact rat brain and after experimentally induced focal ischemia. J. Comp. Neurol. 518, 3752-3770. doi: 10.1002/cne.22422

Virgintino, D., Girolamo, F., Errede, M., Capobianco, C., Robertson, D., Stallcup, W. B., et al. (2007). An intimate interplay between precocious, migrating pericytes and endothelial cells governs human fetal brain angiogenesis. Angiogenesis 10, 35-45. doi: 10.1007/s10456-006-9061-x

Walshe, T. E., Saint-Geniez, M., Maharaj, A. S., Sekiyama, E., Maldonado, A. E., and D'Amore, P. A. (2009). TGF-beta is required for vascular barrier function, endothelial survival and homeostasis of the adult microvasculature. PLOS ONE 4:e5149. doi: 10.1371/journal.pone.0005149

Wang, L., Chopp, M., Teng, H., Bolz, M., Francisco, M. A., Aluigi, D. M., et al. (2011). Tumor necrosis factor $\alpha$ primes cerebral endothelial cells for erythropoietin-induced angiogenesis. J. Cereb. Blood Flow Metab. 31, 640-647. doi: $10.1038 /$ jcbfm. 2010.138

Wang, Y., Kilic, E., Kilic, U., Weber, B., Bassetti, C. L., Marti, H. H., et al. (2005). VEGF overexpression induces post-ischaemic neuroprotection, but facilitates haemodynamic steal phenomena. Brain 128, 52-63. doi: 10.1093/brain/awh325 
Wang, Z. G., Cheng, Y., Yu, X. C., Ye, L. B., Xia, Q. H., Johnson, N. R., et al. (2016). bFGF protects against blood-brain barrier damage through junction protein regulation via PI3K-Akt-Rac1 pathway following traumatic brain injury. Mol. Neurobiol. 53, 7298-7311. doi: 10.1007/s12035-015-9583-6

Watari, K., Nakamura, M., Fukunaga, Y., Furuno, A., Shibata, T., Kawahara, A., et al. (2012). The antitumor effect of a novel angiogenesis inhibitor (an octahydronaphthalene derivative) targeting both VEGF receptor and NF-кB pathway. Int. J. Cancer 131, 310-321. doi: 10.1002/ijc.26356

Werner, G. S. (2002). Promotion of collateral growth by granulocytemacrophage colony-stimulating factor in patients with coronary artery disease. Circulation 105:e175; author reply e175. doi: 10.1161/01.CIR.0000016154. 35658.00

Wilde, G. J., Pringle, A. K., Sundstrom, L. E., Mann, D. A., and Iannotti, F. (2000). Attenuation and augmentation of ischaemia-related neuronal death by tumour necrosis factor-alpha in vitro. Eur. J. Neurosci. 12, 3863-3870. doi: 10.1046/j.1460-9568.2000.00273.x

Winkler, E. A., Bell, R. D., and Zlokovic, B. V. (2011). Central nervous system pericytes in health and disease. Nat. Neurosci. 14, 1398-1405. doi: $10.1038 / \mathrm{nn} .2946$

Xia, Y., Ling, X., Hu, G., Zhu, Q., Zhang, J., Li, Q., et al. (2020). Small extracellular vesicles secreted by human iPSC-derived MSC enhance angiogenesis through inhibiting STAT3-dependent autophagy in ischemic stroke. Stem Cell Res. Ther. 11:313. doi: 10.1186/s13287-020-01834-0

Xu, Q., Briggs, J., Park, S., Niu, G., Kortylewski, M., Zhang, S., et al. (2005). Targeting Stat3 blocks both HIF-1 and VEGF expression induced by multiple oncogenic growth signaling pathways. Oncogene 24, 5552-5560. doi: $10.1038 /$ sj.onc. 1208719

Yang, S., Jin, H., Zhu, Y., Wan, Y., Opoku, E. N., Zhu, L., et al. (2017). Diverse functions and mechanisms of pericytes in ischemic stroke. Curr. Neuropharmacol. 15, 892-905. doi: 10.2174/1570159X15666170112170226

Yao, H., Zhang, Y., Shu, H., Xie, B., Tao, Y., Yuan, Y., et al. (2019). Hyperforin promotes post-stroke neuroangiogenesis via astrocytic il-6-mediated negative immune regulation in the ischemic brain. Front. Cell. Neurosci. 13:201. doi: 10.3389/fncel.2019.00201

Yin, X. X., Zheng, X. R., Peng, W., Wu, M. L., and Mao, X. Y. (2020). Vascular endothelial growth factor (VEGF) as a vital target for brain inflammation during the COVID-19 outbreak. ACS Chem. Neurosci. 11, 1704-1705. doi: 10.1021/acschemneuro.0c00294

Yuan, H. T., Khankin, E. V., Karumanchi, S. A., and Parikh, S. M. (2009). Angiopoietin 2 is a partial agonist/antagonist of Tie2 signaling in the endothelium. Mol. Cell. Biol. 29, 2011-2022. doi: 10.1128/MCB.01472-08

Zhang, H., and Issekutz, A. C. (2002). Down-modulation of monocyte transendothelial migration and endothelial adhesion molecule expression by fibroblast growth factor: reversal by the anti-angiogenic agent SU6668. Am. J. Pathol. 160, 2219-2230. doi: 10.1016/S0002-9440(10)61169-8

Zhang, H., Xiong, X., Liu, J., Gu, L., Li, F., Wan, Y., et al. (2016). Emulsified isoflurane protects against transient focal cerebral ischemia injury in rats via the PI3K/Akt signaling pathway. Anesth. Analg. 122, 1377-1384. doi: 10.1213/ANE.0000000000001172

Zhang, J., Cui, Q., Zhao, Y., Guo, R., Zhan, C., Jiang, P., et al. (2020). Mechanism of angiogenesis promotion with Shexiang Baoxin Pills by regulating function and signaling pathway of endothelial cells through macrophages. Atherosclerosis 292, 99-111. doi: 10.1016/j.atherosclerosis.2019.11.005

Zhang, K., and Luo, J. (2019). Role of MCP-1 and CCR2 in alcohol neurotoxicity. Pharmacol. Res. 139, 360-366. doi: 10.1016/j.phrs.2018.11.030

Zhong, M., Li, N., Qiu, X., Ye, Y., Chen, H., Hua, J., et al. (2020). TIPE regulates VEGFR2 expression and promotes angiogenesis in colorectal cancer. Int. J. Biol. Sci. 16, 272-283. doi: 10.7150/ijbs.37906

Zhou, W., Feng, X., Wu, Y., Benge, J., Zhang, Z., and Chen, Z. (2009). FGF-receptor substrate 2 functions as a molecular sensor integrating external regulatory signals into the FGF pathway. Cell Res. 19, 1165-1177. doi: 10.1038/cr.2009.95

Zhou, Y. F., Chen, A. Q., Wu, J. H., Mao, L., Xia, Y. P., Jin, H. J., et al. (2019). Sema3E/PlexinD1 signaling inhibits postischemic angiogenesis by regulating endothelial DLL4 and filopodia formation in a rat model of ischemic stroke. FASEB J. 33, 4947-4961. doi: 10.1096/fj.201801706RR

Zhu, J., Cao, D., Guo, C., Liu, M., Tao, Y., Zhou, J., et al. (2019). Berberine facilitates angiogenesis against ischemic stroke through modulating microglial polarization via AMPK signaling. Cell. Mol. Neurobiol. 39, 751-768. doi: 10.1007/s10571-019-00675-7

Zhu, Y., Culmsee, C., Roth-Eichhorn, S., and Krieglstein, J. (2001). Beta(2)adrenoceptor stimulation enhances latent transforming growth factor-betabinding protein-1 and transforming growth factor-betal expression in rat hippocampus after transient forebrain ischemia. Neuroscience 107, 593-602. doi: 10.1016/S0306-4522(01)00357-8

Zhu, Z., Xu, T., Guo, D., Huangfu, X., Zhong, C., Yang, J., et al. (2018). Serum hepatocyte growth factor is probably associated with 3-month prognosis of acute ischemic stroke. Stroke 49, 377-383. doi: 10.1161/STROKEAHA.117.019476

Zou, Y., Hu, J., Huang, W., Ye, S., Han, F., Du, J., et al. (2020). Non-mitogenic fibroblast growth factor 1 enhanced angiogenesis following ischemic stroke by regulating the sphingosine-1-phosphate 1 pathway. Front. Pharmacol. 11:59. doi: 10.3389/fphar.2020.00059

Conflict of Interest: The authors declare that the research was conducted in the absence of any commercial or financial relationships that could be construed as a potential conflict of interest.

Copyright (c) 2021 Zhu, Zhang, Zhong, Ye, Hu, Gu and Xiong. This is an open-access article distributed under the terms of the Creative Commons Attribution License (CC $B Y)$. The use, distribution or reproduction in other forums is permitted, provided the original author(s) and the copyright owner(s) are credited and that the original publication in this journal is cited, in accordance with accepted academic practice. No use, distribution or reproduction is permitted which does not comply with these terms. 